\title{
Mitotane induces mitochondrial membrane depolarization and apoptosis in thyroid cancer cells
}

\author{
ATHANASIOS BIKAS ${ }^{1,2}$, KIRK JENSEN ${ }^{3}$, ANEETA PATEL ${ }^{3}$, JOHN COSTELLO ${ }^{3}$, GREGORY KALTSAS ${ }^{1}$, \\ VICTORIA HOPERIA ${ }^{4}$, LEONARD WARTOFSKY ${ }^{5}$, KENNETH BURMAN $^{5}$ and VASYL VASKO ${ }^{3}$ \\ ${ }^{1}$ Department of Pathophysiology, Laiko Hospital, National and Kapodistrian University of Athens, 11527 Athens, \\ Greece; ${ }^{2}$ Department of Internal Medicine, MedStar Georgetown University Hospital, Washington, DC 20007; \\ ${ }^{3}$ Department of Pediatrics, Uniformed Services University of the Health Sciences, Bethesda, MD 20814, USA; \\ ${ }^{4}$ Department of Fundamental Medicine, National University of Kyiv, 01033 Kyiv, Ukraine; ${ }^{5}$ Division of Endocrinology, \\ Department of Internal Medicine, MedStar Washington Hospital Center, Washington, DC 20010, USA
}

Received August 22, 2018; Accepted March 12, 2019

DOI: 10.3892/ijo.2019.4802

\begin{abstract}
Mitotane is used for the treatment of adrenocortical cancer and elicits its anticancer effects via inhibition of mitochondrial respiration. Targeting mitochondria-dependent metabolism has emerged as a promising strategy for thyroid cancer (TC) treatment. We hypothesized that mitotane targets mitochondria and induces apoptosis in TC cells. Cell lines representative of the major histological variants of TC were chosen: Follicular (FTC-133), poorly differentiated (BCPAP), anaplastic (SW1736 and C643) and medullary (TT) TC cells, and were treated with mitotane $(0-100 \mu \mathrm{M})$. Mitochondrial membrane potential, cell viability and apoptosis were examined by JC-1 staining and by western blot analysis using an antibody against caspase-3. The expression of mitochondrial molecules and DNA damage markers and the activation of endoplasmic reticulum (ER) stress were determined by western blotting. The expression of mitochondrial ATP synthase subunit $\beta$ (ATP5B) was examined by immunostaining in 100 human TC tissue samples. Treatment with mitotane $(50 \mu \mathrm{M}$ for $24 \mathrm{~h}$ ) decreased the viability of FTC-133, BCPAP, SW1736, C643 and TT cells by 12, 59, 54, 31 and 66\%, respectively. Morphological evidence of ER stress and overexpression of ER markers was observed in TC cells following exposure to mitotane. The treatment led to increased expression of histone $\gamma \mathrm{H} 2 \mathrm{AX}$, indicating DNA damage, and to caspase- 3 cleavage. Consistent with the results of the cell viability assays, the overexpression of pro-apoptotic genes following treatment with mitotane was more prominent in TC cells harboring mutations in the serine/threonine-protein kinase B-raf gene
\end{abstract}

Correspondence to: Dr Athanasios Bikas, Department of Internal Medicine, MedStar Georgetown University Hospital, 3800 Reservoir Road, Washington, DC 20007, USA

E-mail: athanasios.bikas@medstar.net

Key words: mitotane, thyroid, cancer, thyroid cancer, mitochondria, apoptosis and proto-oncogene tyrosine-protein kinase receptor Ret. Treatment with mitotane was associated with loss of mitochondrial membrane potential and decreased expression of ATP5B, particularly in the medullary TC (MTC)-derived TT cells. Immunohistochemical analysis of mitochondrial ATP5B in human TC specimens demonstrated its overexpression in cancer compared with normal thyroid tissue. The level of ATP5B expression was higher in MTC compared with the follicular, papillary or anaplastic types of TC. Mitotane elicited pleiotropic effects on TC cells, including induction of ER stress, inhibition of mitochondrial membrane potential and induction of apoptosis. The results of the present study suggest that mitotane could be considered as a novel agent for the treatment of aggressive types of TC.

\section{Introduction}

Thyroid cancer (TC) is the most common endocrine malignancy, accounting for $3.2 \%$ of all new malignancies (excluding in situ carcinomas and skin cancers) in the United States, according to statistics from 2012 (1). An increased incidence rate of TC has been reported worldwide and has been attributed largely to the increased detection of small papillary TC, potentially, but not definitively, due to improved detection techniques (2). However, there is also an increase in the incidence of more aggressive types of TC (3). Patients with differentiated TC (DTC) have an excellent prognosis, with the 10-year survival rate ranging between 80 and $95 \%(4,5)$. Recurrence, as well as distant metastases at the time of surgery, however, significantly worsen prognosis. Distant metastases at the time of surgery confer a 10 -year survival rate of $40 \%$ (6), whereas mortality for recurrence has been reported to be as high as $69 \%$ (7). Anaplastic TC (ATC) is a rare histological type of TC, but it is considered one of the most aggressive solid malignancies, with a 1-year survival rate of $20 \%$ (8). Different therapeutic modalities have been implemented for ATC, but no treatment to date has provided significant clinical benefit to patients. Therefore, all patients with ATC should be considered for inclusion in available clinical trials (9). In 2011, medullary TC (MTC) comprised $\sim 3-5 \%$ of all TC cases in 
the United States, but accounted for $15 \%$ of all TC-associated mortalities (10). While representing a histologically distinct entity, MTC, like DTC, has a much worse prognosis when presenting with distant metastases (11). Thus, novel therapeutic strategies are required for aggressive DTC and MTC, as well as for ATC.

Tyrosine kinase inhibitors (TKIs) have been at the forefront in the fight against TC, with 4 such inhibitors already FDA-approved for the treatment of metastatic, radioactive-iodine-refractory DTC and advanced MTC. Several other TKIs are currently under investigation (12). However, treatment with TKIs is commonly associated with significant adverse side-effects and is costly. These characteristics have prompted the evaluation of previously approved non-cancer medications for the treatment of these malignancies. Repositioning of existing FDA-approved medications has emerged as a promising strategy for the treatment of TC (13). As an example, nelfinavir, an HIV protease inhibitor, has demonstrated effectiveness against all histological types of TC in the in vitro setting. More specifically, it has been demonstrated to downregulate tyrosine-protein kinase receptor Ret signaling, inhibit the phosphoinositide 3-kinase/protein kinase B (AKT) and mitogen-activated protein kinase (MAPK)/extracellular signal-regulated kinase (ERK) signaling pathways, and induce apoptosis in MTC cells, while inhibiting proliferation and inducing DNA damage in DTC and ATC cells $(14,15)$. Metformin, widely prescribed to treat diabetes, has been reported to increase progression-free survival in patients with diabetes and TC through the inhibition of ribosomal protein S6 kinase $\beta-1$ and upregulation of AMP-activated protein kinase in in vitro models (16). Metformin also inhibited oxidative phosphorylation in TC cells, and metformin-induced downregulation of mitochondrial glycerol-3-phosphate dehydrogenase was associated with growth inhibitory effects in vitro and in vivo (17).

Previous studies have reported that mitotane, a steroidogenesis inhibitor used for the treatment of adrenocortical carcinoma (ACC) and Cushing's disease (18-20), exerts its anti-neoplastic effects through the inhibition of key mitochondrial enzymes $(21,22)$. Mitotane was reported to induce a mitochondrial respiratory chain defect by inhibiting cytochrome $c$ oxidase (COX) subunits 2 and 4I1 (COX2 and COX4I1). Furthermore, this drug has been reported to induce endoplasmic reticulum (ER) stress and apoptosis in ACC cells (22).

Since the inhibition of mitochondrial functions emerged as a promising strategy for the treatment of TC, we hypothesized that mitotane may be an effective compound against this cancer. In the present study, the effects of mitotane were examined on a number of cell lines representing major histological subtypes of TC. With evidence of growth inhibition and induction of apoptosis at therapeutically achievable concentrations of mitotane, the present results imply the utility of this medication in the treatment of patients with advanced TC.

\section{Materials and methods}

TC cells, culture and reagents. Human TC cell lines derived from follicular (FTC-133), poorly differentiated (BCPAP), anaplastic (SW1736 and C643) and medullary (TT) histotypes were obtained from Dr Motoyasu Saji (Ohio State University, Columbus, $\mathrm{OH}, \mathrm{USA}$ ), with permission from the researchers who originally established the cell lines. Normal human dermal fibroblasts were purchased from Lonza Group Ltd. These cell lines harbor thyroid oncogene mutations, including serine/threonine-protein kinase B-raf V600E (BCPAP and SW1736), phosphatidylinositol 3,4,5-trisphosphate 3-phosphatase and dual-specificity protein phosphatase PTEN (FTC-133), cellular tumor antigen p53 (D259Y mutation; BCPAP), p53 (R248Q mutation; C643), GTPase HRas (C643), and Ret (C634W mutation; TT). All TC cell lines had been tested and authenticated to be of thyroid origin by short tandem repeat profiling analysis. The expression of thyroid-specific genes was confirmed by polymerase chain reaction (PCR) analysis. In the present study, FTC-133, BCPAP, SW1736 and C643 cells were characterized by expression of homeobox protein $\mathrm{Nkx}-2.1$ or thyroid transcription factor 1, and thyroglobulin, and the MTC-derived TT cells expressed thyrocalcitonin.

The cancer cells were propagated in conventional RPMI-1640 medium supplemented with fetal bovine serum (both Thermo Fisher Scientific, Inc.) to $10 \%, 100 \mathrm{U} / \mathrm{ml}$ penicillin and $100 \mathrm{mg} / \mathrm{ml}$ streptomycin in a humidified $5 \% \mathrm{CO}_{2}$ incubator at $37^{\circ} \mathrm{C}$. The cells were sub-cultured with $0.5 \%$ trypsin and $0.02 \%$ EDTA (Sigma-Aldrich; Merck KGaA) until they reached $80 \%$ confluence. All experiments were performed using cells that had been passaged $<20$ times.

In order to express green fluorescent protein (GFP), TT and BCPAP cells were infected with lentiviral particles that did not target any known mammalian mRNA, containing a copGFP-coding construct (cat. no. sc-108084; Santa Cruz Biotechnology, Inc.). Following transduction, the GFP-positive cells were selected with puromycin.

Mitotane [1-(2-chlorophenyl)-1-(4-chlorophenyl)-2,2-dichloroethane] was obtained from Sigma-Aldrich, Merck KGaA. The drug was dissolved in dimethyl sulfoxide (DMSO) and kept as a $100-\mathrm{mM}$ stock solution. A concentration of $50 \mu \mathrm{M}$ is within the threshold of therapeutic serum levels for the treatment of adrenal adenocarcinoma and was the target exposure concentration in the present study. TC cell treatment was performed by supplementation with media containing mitotane at concentrations $0-100 \mu \mathrm{M}$. DMSO exposure of $0.1 \%$ in controls had no effect on the examined cells lines. DMSO controls were treated over the same time course and at the same concentrations of DMSO as was present in the mitotane-treated cells.

Cell proliferation and detection of mitochondrial membrane potential. Cell proliferation rate following treatment with mitotane was determined by cell counting using a Vi-CELL ${ }^{\text {TM }}$ Cell Viability Analyzer (Beckman Coulter, Inc.). Evaluation of mitochondrial membrane potential was performed with a fluorogenic lipophilic cation (JC-1; Cayman Chemical Company), according to the manufacturer's protocol. In cells with hyperpolarized mitochondrial membranes, JC-1 spontaneously forms complexes (J-aggregates) emitting red fluorescence. In cells with depolarized mitochondrial membranes, JC-1 remains in the monomeric form, which does not fluoresce. The detection of mitochondrial membrane potential was performed by fluorescent microscopy (magnification, x40 and x200). All experiments were repeated $\geq 1$ times. 
Cell cycle analysis. FTC-133, BCPAP, SW1736, C643 and TT cells were harvested following 24-h incubation with mitotane (25 and $50 \mu \mathrm{M})$, washed with cold PBS, and fixed in $100 \%$ ice-cold methanol for $1 \mathrm{~h}$. The fixed cells $\left(1 \times 10^{6}\right)$ were incubated with RNase A for $30 \mathrm{~min}$ at room temperature, and stained with $50 \mu \mathrm{g} / \mathrm{ml}$ propidium iodide (PI) solution (Thermo Fisher Scientific, Inc.) at room temperature in the dark for $30 \mathrm{~min}$. Flow cytometry analysis was performed on a BD LSRII flow cytometer (Becton, Dickinson and Company). A 488-nm laser was used for the dye excitation; 595 long pass and $610 / 20$ band pass filters were used for emission detection. Single cells were gated using forward scatter height and area parameters. The single cell population gate was confirmed by using area and width parameters of PI channel. The distribution of cells in the $G_{0} / G_{1}, S$ and $G_{2} / M$ phases of the cell cycle was estimated using ModFit LT version 5.0 analysis software (Verity Software House, Inc.). As an estimate the extent of apoptosis, the percentage of apoptotic cells was calculated in the DNA histograms. The measurements were performed in triplicate.

RNA extraction and reverse transcription-quantitative (RT-q) $P C R$. Total RNA was extracted using the AllPrep DNA/RNA Mini kit (Qiagen, Inc.) according to the manufacturer's protocol. The quality and quantity of total RNA was assessed with a NanoDrop 1000 spectrophotometer (Thermo Fisher Scientific, Inc.). A total of $1 \mu \mathrm{g}$ RNA was reverse transcribed into cDNA with the miScript II RT kit (Qiagen, Inc.) as indicated, at $37^{\circ} \mathrm{C}$ for $1 \mathrm{~h}$ and $95^{\circ} \mathrm{C}$ for $5 \mathrm{~min}$ for termination of the reaction. qPCR screening of cancer-associated genes was performed using a pre-fabricated RT-PCR Human Cancer PathwayFinder Array (PAHS-033ZA; cat. no. 330231) and $\mathrm{RT}^{2} \mathrm{SYBR}^{\circledR}$ Green qPCR Mastermix (both Qiagen, Inc.). The arrays were run on the QuantStudio ${ }^{\mathrm{TM}} 6$ Flex Real-Time PCR System (Thermo Fisher Scientific, Inc.). Cycle thresholds were determined for each gene using the QuantStudio 6 Flex software. The thermocycling conditions were as follows: $95^{\circ} \mathrm{C}$ for 2 min followed by 40 cycles of denaturation at $95^{\circ} \mathrm{C}$ for $15 \mathrm{sec}$ and annealing at $60^{\circ} \mathrm{C}$ for $1 \mathrm{~min}$. Melting curves were determined to ensure amplification of a single product. Cycle threshold values were transferred into a Data Analysis Template spreadsheet (Excel; Microsoft Corporation) and $\Delta \Delta \mathrm{Ct}$ values determined for each gene in the mitotane-treated and control cells. Data analysis was performed following normalization to 5 control genes ( $\beta$-actin, $\beta$-2-microglobulin, GAPDH and hypoxanthine phosphoribosyltransferase 1). Fold-changes in expression of each gene in mitotane-treated samples were compared to control using the comparative Ct method (2- $\left.{ }^{-\Delta \Delta \mathrm{Cq}}\right)(23)$.

The expression levels of phorbol-12-myristate-13-acetate-induced protein 1 (NOXA), p53 upregulated modulator of apoptosis (PUMA) and ATP synthase subunit $\beta$ (ATP5B) were measured using the following primer pairs: NOXA-F, 3'-GCA GAGCTGGAAGTCGAGTG-5'; NOXA-R, 3'-GAGCAGAAG AGTTTGGATATCAG-5'; PUMA-F, 3'-GACGACCTCAAC GCACAGTA-5'; PUMA-R, 3'-AGGAGTCCCATGATGAGA TTGT-5'; ATP5B-F, 3'-TCACCCAGGCTGGTTCAGA-5'; and ATP5B-R 3'-AGTGGCCAGGGTAGGCTGAT-5'. The expression level of the endogenous control (18S) was determined using commercially available primers $\left(\mathrm{RT}^{2} \mathrm{qPCR}\right.$ Primer
Assay for Human 18S; cat. no. PPH05666E; Qiagen, Inc.). For the ATP5B, PUMA and NOXA genes, the PCR reactions were performed in triplicate on a LightCycler 96 (Roche Diagnostics) with the following amplification profile: $50^{\circ} \mathrm{C}$ for $2 \mathrm{~min}$ followed by 40 cycles of denaturation for $10 \mathrm{~min}$ at $95^{\circ} \mathrm{C}$ and annealing for $1 \mathrm{~min}$ at $60^{\circ} \mathrm{C}$. Melting curves were determined to ensure amplification of a single product. Negative cDNA controls were run in parallel with each set of reactions. The amount of transcripts was normalized to that of $18 \mathrm{~S}$. Baseline and threshold values were set by the LightCycler 96 version 1.1 software and data was analyzed and expressed using the $2^{-\Delta \Delta \mathrm{Cq}}$ method of relative quantification.

Protein extraction and western blot analysis. The TC cells were incubated with ice-cold M-PER ${ }^{\mathrm{TM}}$ Mammalian Protein Extraction Reagent (Thermo Fisher Scientific, Inc.), scraped and centrifuged at $4^{\circ} \mathrm{C}$ at $12,000 \mathrm{x}$ g for $10 \mathrm{~min}$, and the supernatant was stored at $-80^{\circ} \mathrm{C}$. The protein concentration was measured using a bicinchoninic acid assay (Pearce; Thermo Fisher Scientific, Inc.), $25 \mu \mathrm{g}$ protein lysate was suspended in reduced SDS sample buffer and the lysates were subjected to SDS-PAGE (4-12\% gels). Non-specific binding was prevented by blocking the membrane with Odyssey ${ }^{\circledR}$ Blocking Buffer (TBS) (LI-COR Biosciences) overnight at $4^{\circ} \mathrm{C}$. The separated proteins were transferred to a nitrocellulose membrane (Thermo Fisher Scientific, Inc.) by electrophoretic blotting, which was then incubated overnight at $4^{\circ} \mathrm{C}$ with primary antibodies against $\beta$-actin (Sigma-Aldrich; Merck KGaA), total AKT, phosphorylated (p-)AKT1/2/3 (Ser473), total ERK, p-ERK1/2, cleaved caspase-3, poly [ADP-ribose] polymerase (PARP), succinate dehydrogenase flavoprotein subunit (SDHA), cytochrome $c, \mathrm{COX} 4, \mathrm{ER}$ oxidoreductin-1 (ERO1), inositol-requiring enzyme 1 (IRE1), and heat shock protein 60 (all Cell Signaling Technology, Inc.); histone $\gamma \mathrm{H} 2 \mathrm{AX}, \mathrm{NADH}$ dehydrogenase $1 \alpha-1$ (NDUFA1) and anti-ATP5B (all Santa Cruz Biotechnology, Inc.) (Table I). The membranes were then incubated with the secondary antibody for $1 \mathrm{~h}$ at room temperature. Detection of proteins was performed using the LI-COR Odyssey imaging system (LI-COR Biosciences).

Immunostaining and human TC tissue samples. Immunostaining was performed on commercially available $5-\mu \mathrm{M}$ thick paraffin-embedded thyroid tissue microarray slides (US Biomax, Inc.). The microarrays included 100 thyroid tissue samples: 10 normal thyroid, 20 follicular TC (FTC), 44 papillary TC (PTC), 6 poorly differentiated TC (PDTC) and 20 MTC samples. Furthermore, formalin-fixed/paraffin-embedded and frozen thyroid tissue samples from 16 patients with thyroid tumors were selected from the thyroid tumor bank at the Uniformed Services University of the Health Sciences (Bethesda, MD, USA) and examined. These samples included normal and tumor tissue from 12 PTC, 3 FTC and 1 MTC case. The sections were deparaffinized in xylene, incubated in alcohol, and following microwave heating with antigen-unmasking solution (Vector Laboratories, Inc.) for $10 \mathrm{~min}$, they were incubated in $3 \%$ hydrogen peroxide for $15 \mathrm{~min}$ to inactivate endogenous peroxidase activity, all at room temperature. The samples were incubated for $10 \mathrm{~min}$ in a working solution of blocking serum (component of the Vectastain Universal Quick kit; Vector Laboratories, Inc.) 
Table I. List of antibodies used in the present study.

\begin{tabular}{|c|c|c|c|}
\hline Antibody & Supplier & Cat. no. & Dilution \\
\hline p-AKT 1/2/3 & Cell Signaling Technology, Inc. & 4060 & $1: 1000$ \\
\hline AKT & & 9272 & $1: 1000$ \\
\hline p-ERK 1/2 & & 4370 & $1: 1000$ \\
\hline ERK & & 4695 & $1: 1000$ \\
\hline Cleaved caspase- 3 & & 9664 & $1: 1000$ \\
\hline SDHA & & 5839 & $1: 1000$ \\
\hline Cytochrome $c$ & & 4280 & $1: 1000$ \\
\hline $\mathrm{COX} 4$ & & 4850 & $1: 1000$ \\
\hline ERO1 & & 3264 & $1: 1000$ \\
\hline IRE1 & & 3294 & $1: 1000$ \\
\hline HSP60 & & 4871 & $1: 1000$ \\
\hline PARP & & 9532 & $1: 1000$ \\
\hline$\gamma \mathrm{H} 2 \mathrm{AX}$ & Santa Cruz Biotechnology, Inc. & sc-101696 & $1: 200$ \\
\hline $\mathrm{H} 2 \mathrm{AX}$ & & sc-54606 & $1: 200$ \\
\hline NDUFA1 & & sc-376357 & $1: 200$ \\
\hline ATP5B & & sc-166443 & $1: 200$ \\
\hline$\beta$-actin & Sigma Aldrich; Merck KGaA & A1978 & $1: 2000$ \\
\hline IRDye 800 CW goat anti-rabbit & LI-COR Biosciences & $926-32211$ & $1: 5000$ \\
\hline IRDye $680 \mathrm{CW}$ goat anti-mouse & & $925-68070$ & $1: 5000$ \\
\hline IRDye $800 \mathrm{CW}$ donkey anti-goat & & $926-32214$ & $1: 5000$ \\
\hline
\end{tabular}

p-, phosphorylated, AKT, protein kinase B; ERK, extracellular signal-regulated kinase; SDHA, succinate dehydrogenase flavoprotein subunit; COX4, cytochrome $c$ oxidase subunit 4; ERO1, endoplasmic reticulum oxidoreductin-1; IRE1, inositol-requiring enzyme 1; HSP60, heat shock protein 60; PARP, poly [ADP-ribose] polymerase; H2AX, histone H2AX; $\gamma$, phosphorylated; NDUFA1, NADH dehydrogenase $1 \alpha-1$; ATP5B, ATP synthase subunit $\beta$.

and incubated at $4{ }^{\circ} \mathrm{C}$ overnight with $2 \mu \mathrm{g} / \mathrm{ml}$ anti-ATP5B antibody (1:100 dilution). Immunostaining was performed using the Vectastain Universal Quick kit (Vector Laboratories, Inc.) according to the manufacturer's instructions. They were then incubated with kit's biotinylated secondary antibody for $10 \mathrm{~min}$, and streptavidin/peroxidase complex working solution for $10 \mathrm{~min}$. Peroxidase staining was revealed using ImmPact DAB peroxidase substrate kit (Vector Laboratories, Inc.). The sections were counterstained with hematoxylin for $30 \mathrm{sec}$ and mounted. All steps were performed at room temperature. Antiserum was omitted in the negative control. The immunostaining was evaluated using an Olympus BX41 microscope (Olympus Corporation). The fluorescent microscopy was performed using a Nikon EclipseTi inverted microscope (magnification, $\mathrm{x} 40$ and x200; Nikon Corporation).

For quantification of the ATP5B expression, $\geq 200$ cells in three different areas of tumor were examined, and the percentage of positive cells was calculated. The results of staining were interpreted as follows: Negative, no staining or focal/low intensity of staining in $<50 \%$ of cells; and positive, strong staining in $>50 \%$ of cells. The intensity of the immunostaining was scored independently by two investigators.

Statistical analysis. The data were analyzed using SSPS version 22.0 software. For non-parametric data, the Kruskal-Wallis test was used, followed by a Bonferroni correction for multiple comparisons. For parametric data, 2 -sample Student's t-test was used. $\mathrm{P}<0.05$ was considered to indicate statistically significant differences. UCSC Xena (https://xenabrowser.net/heatmap/) was used to explore functional genomic data sets for links between ATP5B expression and clinical prognosis. UCSC Xena allows for exploration of genomic data sets to discover associations between genomic and/or phenotypic variable, and to determine if a gene affects survival through Kaplan-Meier survival analysis.

\section{Results}

Mitotane inhibits TC cell viability. TC cells FTC-133, BCPAP, SW1736, C643 and TT were treated with increasing concentrations of mitotane for $24 \mathrm{~h}$, and the number of viable cells was determined by direct cell counting using the Vi-CELL Cell Viability Analyzer. As demonstrated in Fig. 1A, treatment with mitotane was associated with a decrease in the number of viable cells in all examined cell lines. The cells responded to treatment in a dose-dependent manner, and demonstrated differential sensitivity to mitotane. BRAF-mutant BCPAP and SW1736 cells, and Ret-positive TT cells were more sensitive to mitotane compared with the PTEN-deficient FTC-133 or HRas-mutant C643 cells. Treatment with mitotane (50 $\mu \mathrm{M}$ for $24 \mathrm{~h}$ ) decreased the viability of FTC-133, BCPAP, SW1736, 


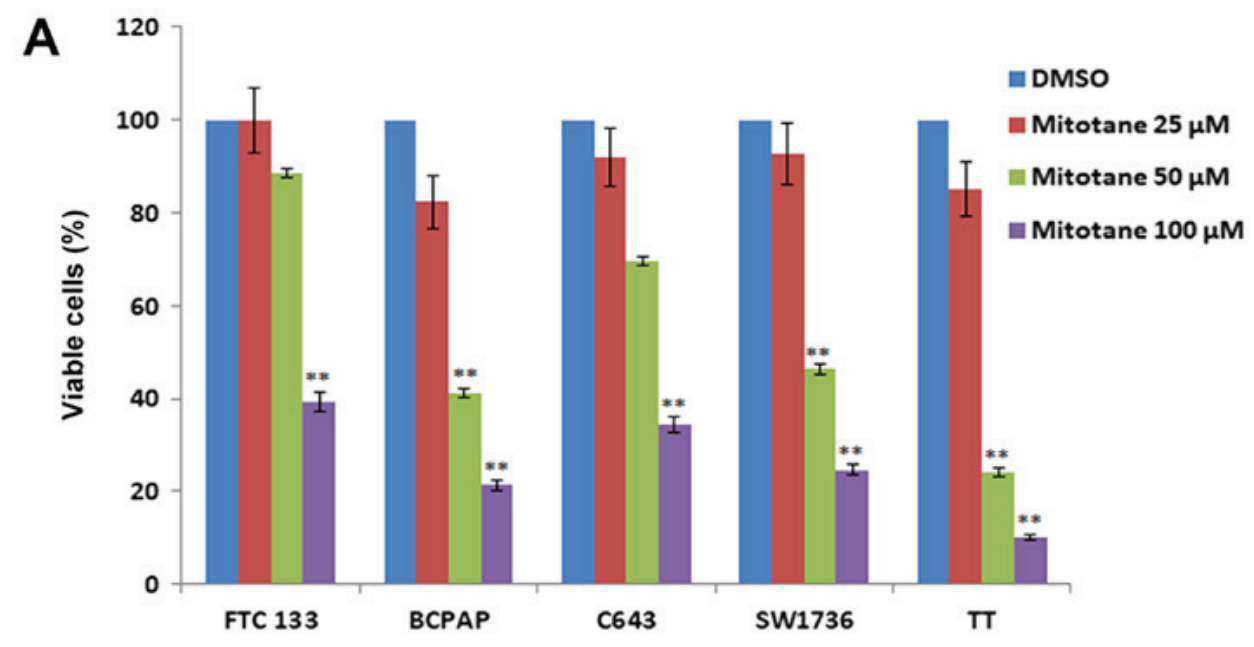

B

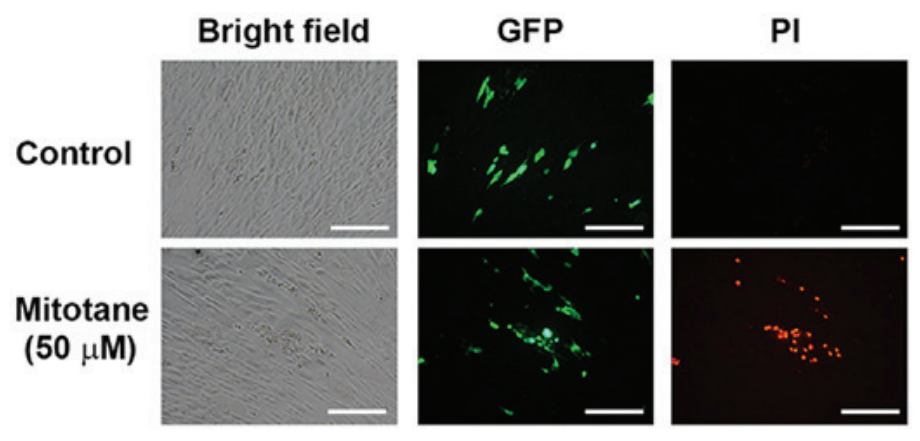

C
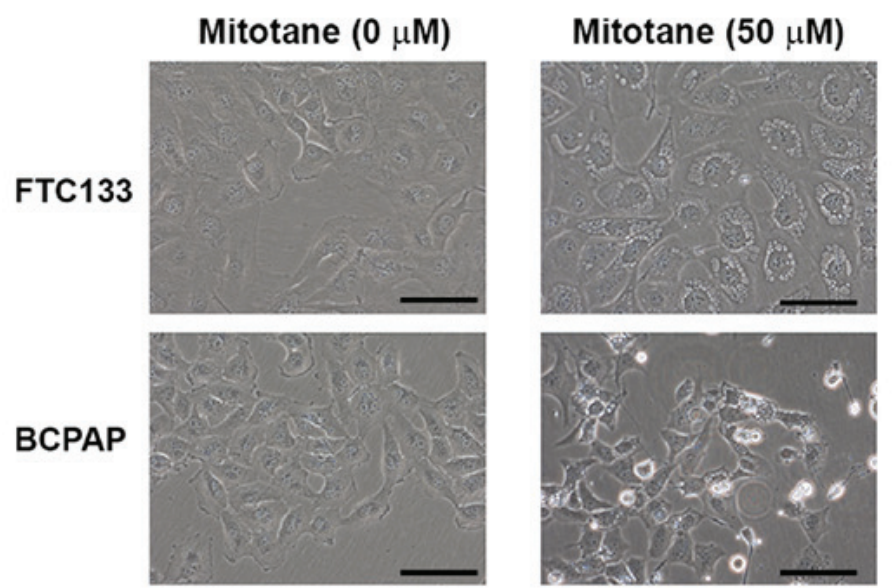

\begin{tabular}{|c|c|c|c|c|c|c|}
\hline D & FTC133 & BCPAP & SW1736 & & C643 & TT \\
\hline Mitotane $(\mu \mathrm{M})$ & $\begin{array}{llll}0 & 25 & 50 & 100\end{array}$ & $\begin{array}{lllll}0 & 25 & 50 & 100\end{array}$ & $\begin{array}{lllll}0 & 25 & 50 & 100\end{array}$ & 0 & $\begin{array}{lll}25 & 50 & 100\end{array}$ & $\begin{array}{lllll}0 & 25 & 50 & 100\end{array}$ \\
\hline ERO1 & $---\rightarrow$ & $--\omega-$ & ---2 & - & --- & $--\theta=$ \\
\hline IRE1 & $=--$ & $\Xi \equiv--$ & $-- \pm=$ & $=$ & --- & $-\infty$ \\
\hline$\beta$-actin & $\rightarrow$ & $x-3=$ & •ேー & 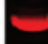 & $=$ & $0--2$ \\
\hline
\end{tabular}

Figure 1. Mitotane inhibits cell viability and induces ER stress in thyroid cancer cell lines. (A) Inhibition of thyroid cancer cell viability following treatment with increasing concentrations of mitotane $(10,50$ and $100 \mu \mathrm{M})$ for $24 \mathrm{~h}$. BCPAP, SW1736 and TT cells indicated increased sensitivity to mitotane. ${ }^{* *} \mathrm{P}<0.01$ versus no-mitotane control. The data are presented as the mean \pm standard deviation. (B) TT cells expressing GFP were co-cultured with human fibroblasts and treated with 0 and $50 \mu \mathrm{M}$ mitotane for $24 \mathrm{~h}$ (bright-field microscopy images are displayed in the left column). TT-GFP cells were easily identified from human fibroblasts by fluorescent microscopy (middle column). Nuclear accumulation of propidium iodide, indicating cell death was detected in GFP-positive TT cells, but not in fibroblasts (right column), demonstrating differential sensitivity to treatment with $50 \mu \mathrm{M}$ mitotane for $24 \mathrm{~h}$. Scale bar, $100 \mu \mathrm{m}$. (C) Direct bright-field microscopy images of FTC-133 and BCPAP cells following exposure to 0 or $50 \mu \mathrm{M}$ mitotane for $24 \mathrm{~h}$. Formation of large cytoplasmic vacuoles, indicative of ER stress induction, was observed in mitotane-treated FTC-133 cells. Cellular shrinkage, nuclear fragmentation, plasma membrane blebbing and cell detachment from the plate, indicating apoptosis, were observed in the mitotane-treated BCPAP cells. Scale bar, $20 \mu \mathrm{m}$. (D) Western blot analysis revealed that treatment with mitotane for $24 \mathrm{~h}$ increased the protein level of IRE1 and ERO1 in FTC-133, BCPAP, SW1736, C643 and TT cells, indicating induction of ER stress. GFP, green fluorescent protein; PI, propidium iodide; ER, endoplasmic reticulum; IRE1, inositol-requiring enzyme 1; ERO1, endoplasmic reticulum oxidoreductin-1. 
C643 and TT cells by 12, 59, 54, 31 and 66\%, respectively. This degree of inhibition was statistically significant for the BCPAP, SW1736 and TT cells compared with that in the control cells $(\mathrm{P} \leq 0.01)$.

The effects of mitotane on TC cells and fibroblasts. To further confirm that TC cells are sensitive to mitotane, co-culture experiments were performed. MTC-derived TT cells expressing GFP (TT-GFP cells) were co-cultured with human fibroblasts in the same plate, and subsequently treated with $50 \mu \mathrm{M}$ mitotane for $24 \mathrm{~h}$. The TT-GFP cells formed cellular clusters that were barely distinguishable from the fibroblasts by bright-field microscopy, but easily identifiable by fluorescence microscopy (Fig. 1B). Treatment with mitotane was associated with progressive decrease in the number of TT-GFP cells (data not shown). To demonstrate that treatment with mitotane leads to death of TT cells but not fibroblasts, PI staining was performed. Nuclear accumulation of PI, indicating dead cells, was detected in the TTT-GFP cells, but not in the fibroblasts (Fig. 1B). Similar results were observed for mitotane-treated GFP-positive BCPAP cells co-cultured with fibroblasts (data not shown).

Mitotane induces ER stress in TC cells. The morphological changes in mitotane-treated TC cells were monitored. Treatment with $50 \mu \mathrm{M}$ mitotane for $24 \mathrm{~h}$ was associated with the formation of large cytoplasmic vacuoles in all examined thyroid cells, suggesting the induction of ER stress (Fig. 1C). In addition, the morphological features of apoptosis, including cellular shrinkage, nuclear fragmentation, plasma membrane blebbing and cell detachment from the plate, were observed in BCPAP (Fig. 1C), SW1736 and TT cells (data not shown) following exposure to mitotane. These morphological changes were observed over time and the effects of mitotane withdrawal from the medium were investigated. In the FTC-133 cells, mitotane treatment for $12 \mathrm{~h}$ was associated with the formation of vacuoles in the cytoplasm, and over time the number and size of vacuoles progressively increased. For cells exposed to the drug for $16 \mathrm{~h}$, the replacement of the medium to drug-free conditions induced a reversion of the cellular phenotype. At $20 \mathrm{~h}$ ( $4 \mathrm{~h}$ after the medium change), the morphological features of pre-treated FTC-133 cells were indistinguishable from control untreated cells. Notably, following exposure to $50 \mu \mathrm{M}$ mitotane for $24 \mathrm{~h}$, the switch to mitotane-free media was sufficient for the restoration of normal morphology in the FTC-133 and C643 cells, but not in the BCPAP, SW1736 and TT cells. Treatment with a $100 \mu \mathrm{M}$ concentration for $24 \mathrm{~h}$ induced irreversible morphological changes among all examined TC cell lines (data not shown).

To confirm that mitotane induces ER stress in TC cells, the expression of ER-stress-associated proteins in mitotane-treated cells was examined by western blotting. Treatment with $50 \mu \mathrm{M}$ of the drug for $24 \mathrm{~h}$ increased the protein level of IRE1 in the FTC-133, BCPAP, SW1736 and TT cells, but not in the C643 cells. In all examined cells, 24-h exposure to $100 \mu \mathrm{M}$ mitotane was associated with upregulation of ERO1, confirming that ER stress serves a role in the response of TC cells to treatment with this compound (Fig. 1D). Together, these data reveal that TC cells exhibit differing abilities to recover from mitotane-induced ER stress.
The effects of mitotane on the cell cycle of TC cells. Suppression of cell proliferation in cancer cells is usually associated with concomitant cell cycle arrest and activation of cell death pathways. Therefore, the contribution of cell cycle arrest and apoptosis to the observed proliferation inhibition following treatment with mitotane was examined. As observed in Fig. 2A, the cell cycle was arrested at the $G_{1}$ phase for mitotane-treated BCPAP, C643, SW1736 and TT cells compared with untreated cells. For the FTC-133 cells, the drug treatment had minimal effects on the cell cycle; the percentage of cells in $\mathrm{G}_{1}$ increased from 53.9 to $55.5 \%$, and the percentage of $\mathrm{G}_{2}$ cells decreased from 11.7 to $9.5 \%$.

In addition, flow cytometry was used to quantify the effects of mitotane on TC cell apoptosis (with the sub- $\mathrm{G}_{1}$ fraction shown in Fig. 2A). For the FTC-133, C643 and SW1736 cells, 24-h treatment with 25 and $50 \mu \mathrm{M}$ mitotane did not lead to induction of apoptosis. Treatment of the BCPAP cells with concentrations 25 and $50 \mu \mathrm{M}$ resulted in the detection of 21.2 and $24.9 \%$ apoptotic cells, respectively. For the TT cells, treatment with 25 and $50 \mu \mathrm{M}$ of the drug also resulted in induction of apoptosis with a detection of 48.2 and $55.4 \%$ apoptotic cells, respectively.

Mitotane affects the expression of cancer-associated genes in TC cells. To clarify the cellular mechanisms controlling the response of TC cells to mitotane, we examined the expression of genes with an established role in cancer using a commercial RT-PCR cancer array. The tested genes are listed in Table II, along with the fold change (upregulation or downregulation) in each of the tested TC cell lines following 24-h treatment with $50 \mu \mathrm{M}$ mitotane. Treatment with mitotane was associated with cell type-specific changes in the mRNA levels of cancer-associated genes. Only 2 of the 84 examined genes, heme oxygenase 1 (HMOX1) and DNA-damage-inducible transcript 3 (DDIT3), were affected by mitotane treatment in all tested TC cells. Exposure to this drug was associated with increased expression of HMOX1 and DDIT3, molecules known as key mediators of cellular response to stress and DNA damage.

Notably, mitotane significantly inhibited expression of the $\mathrm{X}$-linked inhibitor of apoptosis gene XIAP in the MTC-derived TT cells, but not in other cell lines. Therefore, additional experiments were performed in order to clarify the effects of mitotane on apoptosis-associated genes. The expression of apoptotic markers NOXA and PUMA were investigated using RT-qPCR. No significant difference was noted in the NOXA expression in mitotane-treated FTC-133, BCPAP, SW1736 and C643 cells, but a 4.28-fold increase was observed in the TT cells (data not shown). Also, no significant effect was noted in the mRNA levels of PUMA in the FTC-133 and C643 cells following exposure to mitotane, but they were increased in the BCPAP, SW1736 and TT cells by 5.5-, 2.6- and 31.5-fold, respectively (Fig. 2B). These data demonstrate that exposure to mitotane is associated with changes in the mRNA level of genes regulating the cellular response to stress, DNA damage and apoptosis.

Mitotane induces DNA damage and apoptosis in TC cells. To confirm that mitotane-induced toxicity in TC cells is associated with the induction of DNA damage and apoptosis, western blot 


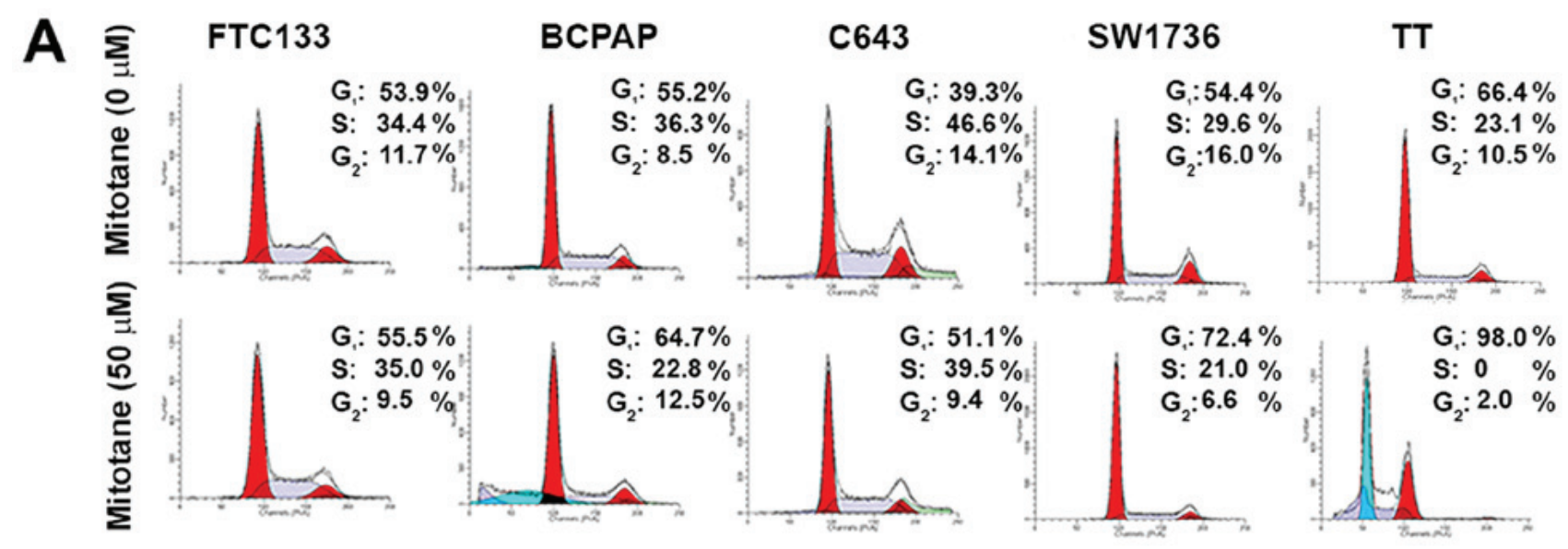

B
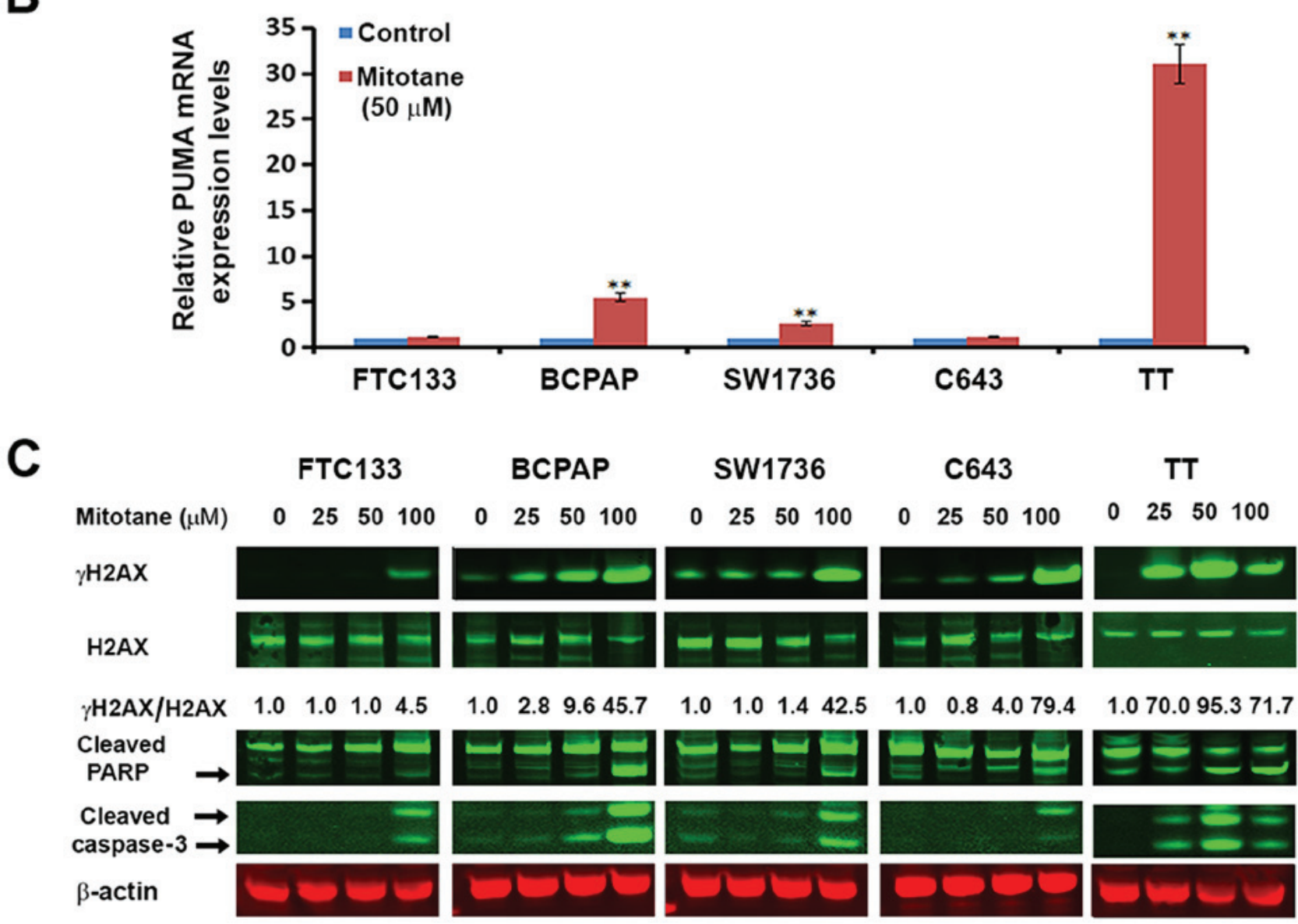

Figure 2. Mitotane induces cell cycle arrest, apoptosis and DNA damage in thyroid cancer cell lines. (A) Mitotane-induced thyroid cancer cell cycle arrest. FTC-133, BCPAP, C643, SW1736 and TT cells were cultured with or without $50 \mu \mathrm{M}$ mitotane for $24 \mathrm{~h}$. The DNA content was measured by flow cytometry to determine the cell cycle fractions. Representative flow cytometry histograms are presented, and the fraction of cells in each cell cycle phase is indicated. (B) Mitotane increases the mRNA levels of the pro-apoptotic gene PUMA in thyroid cancer cells harboring BRAF mutations (BCPAP and SW1736), and MTC-derived proto-oncogene tyrosine-protein kinase receptor Ret-positive TT cells. The fold-changes presented are normalized to the control group for each cell type. ${ }^{* *} \mathrm{P}<0.01$ versus control. The data are presented as the mean \pm standard deviation. (C) Treatment with mitotane for $24 \mathrm{~h}$ induces DNA damage in a dose-dependent and cell type-specific manner as demonstrated by the upregulation of $\gamma \mathrm{H} 2 \mathrm{AX}$, detected by western blotting. Total $\mathrm{H} 2 \mathrm{AX}$ and $\gamma \mathrm{H} 2 \mathrm{AX}$ are presented with the numbers below the bands indicating the ratio of phosphorylated to total protein, demonstrating upregulation of $\gamma \mathrm{H} 2 \mathrm{AX}$. Treatment for $24 \mathrm{~h}$ also induced cell death in a dose-dependent and cell type-specific manner, as demonstrated by the upregulation of cleaved PARP and cleaved caspase-3. MTC-derived TT cells were the most sensitive to treatment, with upregulation of cleaved caspase- 3 following exposure to $25 \mu \mathrm{M}$ mitotane. MTC, medullary thyroid cancer; PUMA, p53 upregulated modulator of apoptosis; H2AX, histone H2AX; $\gamma$, phosphorylated; PARP, poly [ADP-ribose] polymerase.

analysis was performed using antibodies against $\gamma \mathrm{H} 2 \mathrm{AX}$ and cleaved caspase-3 (Fig. 2C). Treatment with mitotane led to an increased expression of $\gamma \mathrm{H} 2 \mathrm{AX}$ in a dose-dependent manner. The induction of $\gamma \mathrm{H} 2 \mathrm{AX}$ expression was more prominent in
BCPAP, SW1736 and TT cells than in FTC-133 and C643 cells. Exposure to this drug also resulted in the upregulation of caspase-3 and PARP cleavage in a dose-dependent and cell type-specific manner (Fig. 2C). In the MTC-derived 
Table II. Fold changes in gene expression in TC cells treated with mitotane, as tested using the RT-PCR cancer array. ${ }^{a}$

\begin{tabular}{|c|c|c|c|c|c|c|}
\hline No. & Gene & ВСРАР & SW1736 & FTC-133 & C643 & $\mathrm{TT}$ \\
\hline 1 & ACLY & -1.58 & -1.36 & -1.17 & 1.42 & 1.46 \\
\hline 2 & ACSL4 & 1.34 & 1.27 & 1.44 & 1.51 & 1.12 \\
\hline 3 & $\mathrm{ADM}$ & 1.39 & 1.29 & 1.62 & -2.35 & 1.36 \\
\hline 4 & ANGPT1 & 1.22 & $-9.49^{b}$ & -1.95 & -2.48 & 2.80 \\
\hline 5 & ANGPT2 & -1.71 & 1.93 & $-3.04^{b}$ & 1.01 & 2.89 \\
\hline 6 & APAF1 & -1.84 & $-3.27^{b}$ & -1.25 & -1.50 & 2.08 \\
\hline 7 & ARNT & 1.81 & -1.49 & -1.31 & 1.54 & 2.57 \\
\hline 8 & ATP5A1 & 2.19 & 1.97 & 2.07 & 1.77 & 1.24 \\
\hline 9 & AURKA & -1.35 & -1.18 & -2.18 & 1.37 & $-19.69^{b}$ \\
\hline 10 & BCL2L11 & 2.13 & $-7.08^{b}$ & -2.02 & -1.06 & $3.15^{\mathrm{b}}$ \\
\hline 11 & BIRC3 & 1.38 & -1.30 & $-3.39^{b}$ & $5.48^{\mathrm{b}}$ & $9.55^{\mathrm{b}}$ \\
\hline 12 & BMI1 & 1.29 & 1.12 & 1.26 & 1.86 & 2.66 \\
\hline 13 & CA9 & -1.22 & $-56.06^{\mathrm{b}}$ & $-4.02^{b}$ & 1.80 & 2.44 \\
\hline 14 & CASP2 & 1.04 & 1.07 & -1.59 & 1.23 & -1.92 \\
\hline 15 & CASP7 & 2.71 & 1.07 & 1.52 & 1.65 & 1.33 \\
\hline 16 & CASP9 & 2.57 & 1.60 & -1.03 & 2.65 & 1.24 \\
\hline 17 & CCL2 & 2.90 & $-59.40^{\mathrm{b}}$ & 1.82 & 1.80 & 1.53 \\
\hline 18 & CCND2 & $12.96^{\mathrm{b}}$ & $-8.70^{\mathrm{b}}$ & -2.35 & 2.01 & -2.23 \\
\hline 19 & CCND3 & 1.50 & -1.64 & -1.95 & 1.19 & -1.63 \\
\hline 20 & $\mathrm{CDC} 20$ & 1.81 & -1.42 & -1.22 & -1.13 & -2.07 \\
\hline 21 & $\mathrm{CDH} 2$ & -1.87 & -2.86 & 2.07 & -1.50 & 1.04 \\
\hline 22 & CFLAR & 1.50 & -2.49 & 1.66 & 1.52 & 2.72 \\
\hline 23 & COX5A & 1.11 & -1.38 & 1.14 & -1.06 & -1.31 \\
\hline 24 & СРТ2 & 1.16 & -1.23 & -2.65 & 1.39 & -1.26 \\
\hline 25 & DDB2 & -1.64 & -2.69 & -1.84 & -1.94 & $5.96^{\mathrm{b}}$ \\
\hline 26 & DDIT3 & $8.11^{\mathrm{b}}$ & $3.08^{\mathrm{b}}$ & $3.23^{\mathrm{b}}$ & $8.86^{\mathrm{b}}$ & $26.02^{\mathrm{b}}$ \\
\hline 27 & DKC1 & $5.02^{\mathrm{b}}$ & 1.47 & 2.32 & 1.69 & 1.73 \\
\hline 28 & DSP & 2.11 & -2.88 & $-56.57^{\mathrm{b}}$ & 2.27 & 1.24 \\
\hline 29 & E2F4 & 1.12 & 1.32 & 1.51 & 1.61 & -1.05 \\
\hline 30 & EPO & 2.90 & 1.47 & 1.82 & 1.80 & 2.50 \\
\hline 31 & ERCC3 & 1.14 & 1.26 & -1.05 & 1.89 & 1.96 \\
\hline 32 & ERCC5 & 1.89 & 1.32 & -1.03 & $4.38^{\mathrm{b}}$ & $3.93^{b}$ \\
\hline 33 & ETS2 & 1.74 & -1.09 & -1.63 & 2.14 & 1.92 \\
\hline 34 & FASLG & 2.90 & 1.47 & 1.82 & 1.80 & -1.91 \\
\hline 35 & FGF2 & $7.18^{\mathrm{b}}$ & 1.68 & 1.00 & 1.36 & -2.96 \\
\hline 36 & FLT1 & 2.90 & $-3.25^{\mathrm{b}}$ & 1.82 & $4.69^{b}$ & -2.08 \\
\hline 37 & FOXC2 & -1.59 & 1.47 & 1.82 & -1.70 & $9.12^{\mathrm{b}}$ \\
\hline 38 & G6PD & 1.00 & -1.44 & -1.14 & -2.19 & 1.32 \\
\hline 39 & GADD45G & 2.90 & 1.47 & 1.82 & 1.80 & 1.21 \\
\hline 40 & GPD2 & -1.29 & -1.12 & -2.31 & -1.57 & 1.81 \\
\hline 41 & GSC & 2.90 & 1.47 & 1.82 & 1.80 & 2.50 \\
\hline 42 & HMOX1 & $7.00^{\mathrm{b}}$ & $23.76^{\mathrm{b}}$ & $10.07^{\mathrm{b}}$ & $3.42^{\mathrm{b}}$ & $21.58^{\mathrm{b}}$ \\
\hline 43 & IGFBP3 & 1.36 & -1.12 & 1.09 & 2.24 & 1.43 \\
\hline 44 & IGFBP5 & $-4.69^{b}$ & $-9.43^{b}$ & $-16.10^{\mathrm{b}}$ & $-22.21^{\mathrm{b}}$ & 2.42 \\
\hline 45 & IGFBP7 & 1.43 & -1.46 & 1.72 & -1.76 & 1.16 \\
\hline 46 & KDR & -1.76 & 1.47 & $-4.35^{\mathrm{b}}$ & 1.80 & -1.80 \\
\hline 47 & KRT14 & -1.33 & 2.62 & $5.21^{\mathrm{b}}$ & 1.80 & 1.75 \\
\hline 48 & LDHA & -1.45 & -2.45 & -1.14 & 1.13 & 1.61 \\
\hline 49 & LIG4 & $3.33^{\mathrm{b}}$ & 1.62 & -1.96 & 1.88 & 1.48 \\
\hline 50 & LPL & $5.24^{\mathrm{b}}$ & $-4.64^{b}$ & -2.21 & 1.80 & $3.76^{\mathrm{b}}$ \\
\hline 51 & MAP2K1 & 1.28 & 1.15 & 2.39 & $3.87^{\mathrm{b}}$ & $3.36^{\mathrm{b}}$ \\
\hline 52 & MAP2K3 & 2.59 & 2.04 & 2.14 & 2.99 & -1.33 \\
\hline
\end{tabular}


Table II. Continued.

\begin{tabular}{|c|c|c|c|c|c|c|}
\hline No. & Gene & BCPAP & SW1736 & FTC-133 & C643 & $\mathrm{TT}$ \\
\hline 53 & MAPK14 & -1.05 & -1.57 & -1.22 & 1.38 & 2.47 \\
\hline 54 & MCM2 & 1.34 & 1.11 & -1.73 & 1.31 & 1.22 \\
\hline 55 & MKI67 & -1.55 & 1.03 & -1.69 & -1.87 & 1.13 \\
\hline 56 & NOL3 & 1.12 & $-3.18^{b}$ & -1.25 & 1.45 & 1.25 \\
\hline 57 & OCLN & 1.44 & -2.48 & $4.07^{\mathrm{b}}$ & 1.74 & 2.15 \\
\hline 58 & PFKL & -1.13 & -1.81 & 1.21 & 1.67 & 1.64 \\
\hline 59 & PGF & 1.75 & -1.57 & -1.04 & 1.65 & -1.83 \\
\hline 60 & PINX1 & -1.69 & -1.85 & $-18.59^{b}$ & 2.04 & -2.73 \\
\hline 61 & POLB & 1.11 & -1.93 & -1.70 & -1.01 & 1.23 \\
\hline 62 & PPP1R15A & $5.22^{\mathrm{b}}$ & 2.48 & -1.21 & $6.14^{\mathrm{b}}$ & $45.75^{\mathrm{b}}$ \\
\hline 63 & SERPINB2 & $7.77^{b}$ & $13.44^{\mathrm{b}}$ & 1.82 & $9.34^{\mathrm{b}}$ & -1.33 \\
\hline 64 & SERPINF1 & $7.41^{b}$ & -1.03 & -1.96 & 1.80 & 1.79 \\
\hline 65 & SKP2 & -1.61 & -1.32 & -1.41 & -1.44 & -1.18 \\
\hline 66 & SLC2A1 & -1.84 & -2.25 & 1.85 & -1.42 & 1.50 \\
\hline 67 & SNAI1 & 2.90 & $-8.64^{b}$ & -1.43 & -1.42 & 2.37 \\
\hline 68 & SNAI2 & 1.51 & $11.87^{\mathrm{b}}$ & $-12.22^{b}$ & 1.26 & 1.19 \\
\hline 69 & SNAI3 & 2.90 & -1.63 & 1.82 & 1.80 & -2.20 \\
\hline 70 & SOD1 & 1.50 & -1.90 & -1.27 & -1.16 & 1.01 \\
\hline 71 & SOX10 & 2.90 & 2.36 & 1.82 & 2.46 & 1.79 \\
\hline 72 & STMN1 & -1.42 & -1.62 & -1.92 & $-4.37^{\mathrm{b}}$ & $-374.29^{b}$ \\
\hline 73 & TBX2 & 2.90 & -1.57 & 2.11 & 2.10 & -1.23 \\
\hline 74 & TEK & 2.90 & 1.47 & -1.22 & 1.80 & 1.37 \\
\hline 75 & TEP1 & 2.41 & 1.76 & 2.03 & 1.56 & 2.09 \\
\hline 76 & TERF1 & 1.11 & -2.00 & -1.14 & 1.58 & -1.26 \\
\hline 77 & TERF2IP & $4.01^{\mathrm{b}}$ & 1.84 & 1.60 & $3.53^{\mathrm{b}}$ & $3.21^{\mathrm{b}}$ \\
\hline 78 & TINF2 & -1.38 & -1.03 & -1.04 & 1.38 & -1.63 \\
\hline 79 & TNKS & 1.01 & -1.42 & -2.57 & 1.68 & 2.04 \\
\hline 80 & TNKS2 & 1.15 & 1.09 & 1.45 & 1.86 & $4.21^{\mathrm{b}}$ \\
\hline 81 & UQCRFS1 & 1.74 & -1.05 & -1.80 & 1.35 & 1.71 \\
\hline 82 & VEGFC & 1.21 & 2.13 & -1.48 & $4.30^{\mathrm{b}}$ & -2.86 \\
\hline 83 & WEE1 & -1.18 & -1.14 & -1.41 & 1.11 & $6.83^{b}$ \\
\hline 84 & XIAP & 1.05 & 2.03 & -1.47 & 1.48 & $-40.74^{b}$ \\
\hline
\end{tabular}

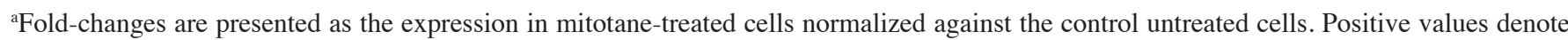
upregulation and negative values indicate downregulation. ${ }^{b}$ Fold-change $\geq 3$.

TT cells, caspase-3 cleavage was detected following 24-h exposure to $25 \mu \mathrm{M}$ mitotane, in the B-raf-positive BCPAP cells it was detected following treatment with a concentration of $50 \mu \mathrm{M}$, and the $100 \mu \mathrm{M}$ concentration led to its detection in all cells. Combined, these data suggest that treatment with mitotane leads to the induction of DNA damage and apoptosis in TC cells, particularly in cells harboring BRAF and RET mutations.

Mitotane affects mitochondrial function and expression of mitochondrial proteins. Mitochondria serve a critical role in the execution of apoptotic programming, and a previous study demonstrated the effects of mitotane on their activity (21). Therefore, the mitochondrial membrane potential was examined in TC cells following treatment with increasing concentrations of mitotane (0-50 $\mu \mathrm{M})$. A dose-dependent decrease in JC-1 fluorescence was observed, indicative of progressive loss of mitochondrial activity. Treatment with $30 \mu \mathrm{M}$ of the drug was sufficient to initiate inhibition of mitochondrial membrane potential in all examined TC cell lines (Fig. 3A).

Additionally, the levels of mitochondrial proteins NDUFA1 (complex 1), SDHA (complex 2), cytochrome $c$, COX4 (complex 4) and ATP5B (complex 5) were assessed in the TC cells by western blot analysis. Mitotane treatment resulted in a decrease in the levels of factors regulating oxidative respiration in a dose-dependent and cell type-specific manner. In all examined cell types, exposure to $50 \mu \mathrm{M}$ mitotane led to a decrease in the protein level of ATP5B (Fig. 3B). The mRNA levels of ATP5B were also assessed by RT-qPCR in mitotane-treated TC cells and untreated controls. Treatment with 
A Mitotane $(\mu \mathrm{M}) \quad 0$

FTC133

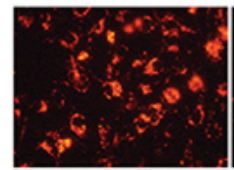

10

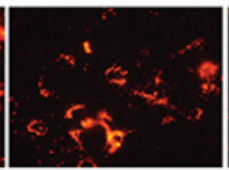

BCPAP
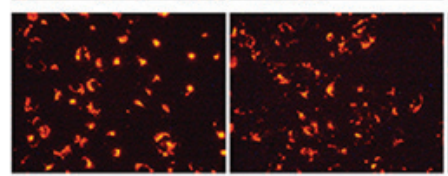

SW1736
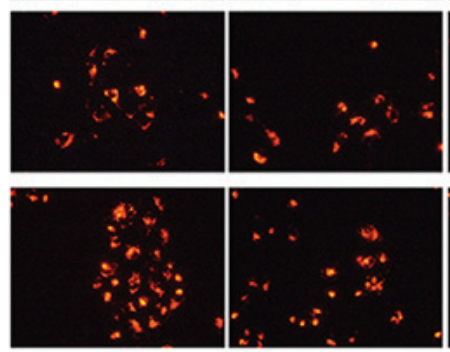

TT
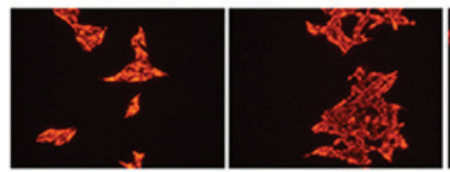

FTC133

B

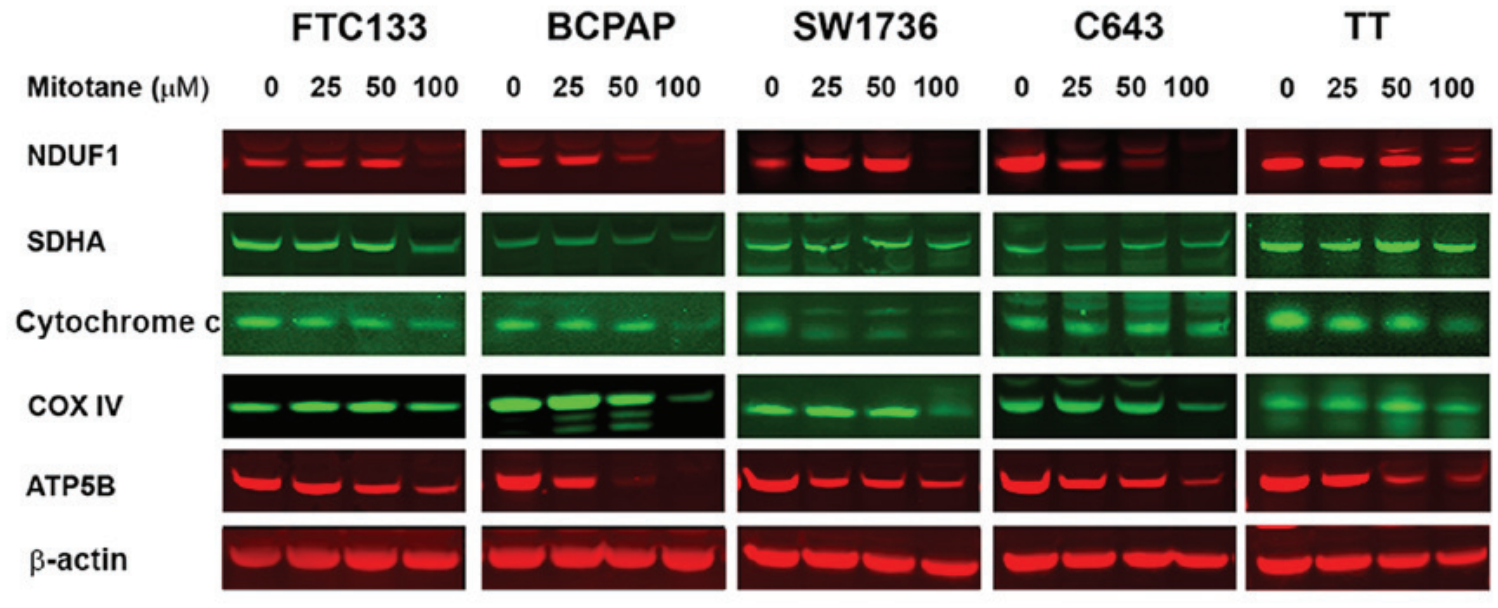

C
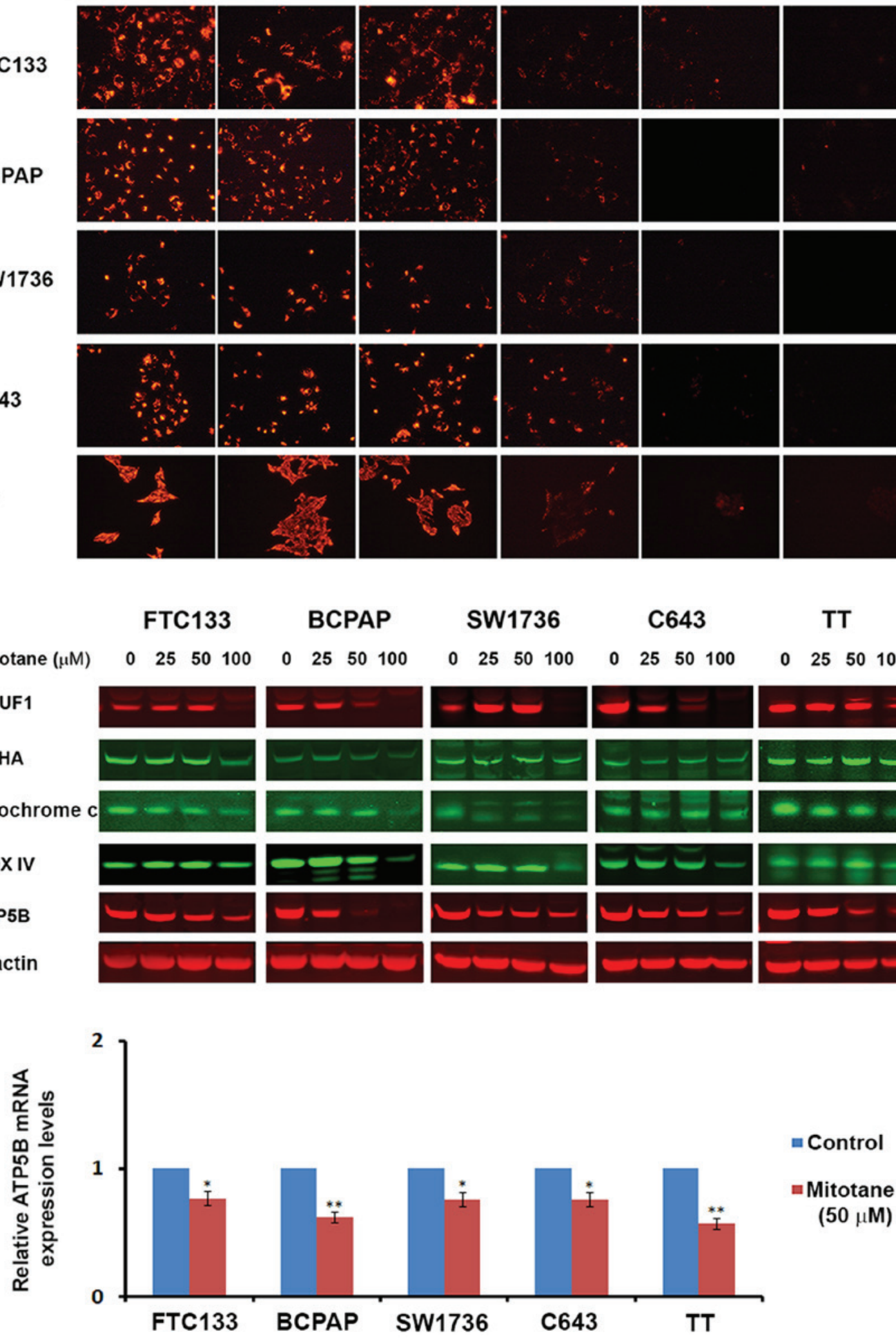

30

40
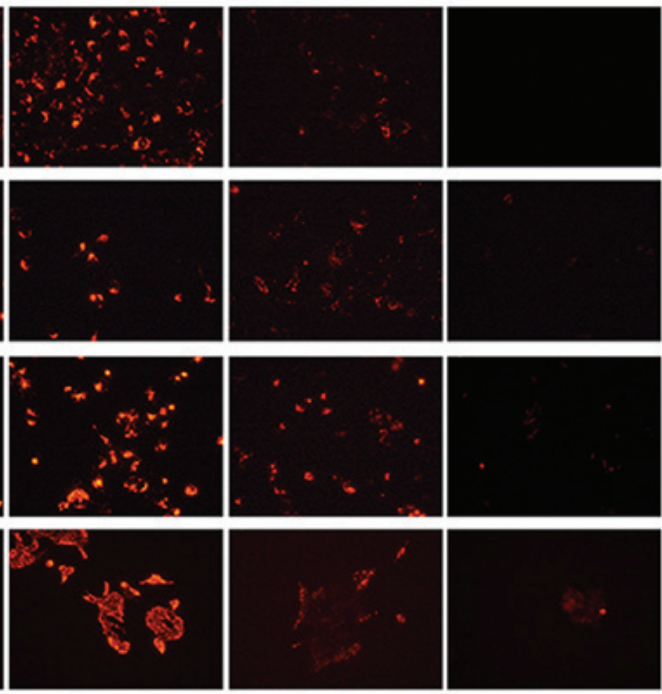

50
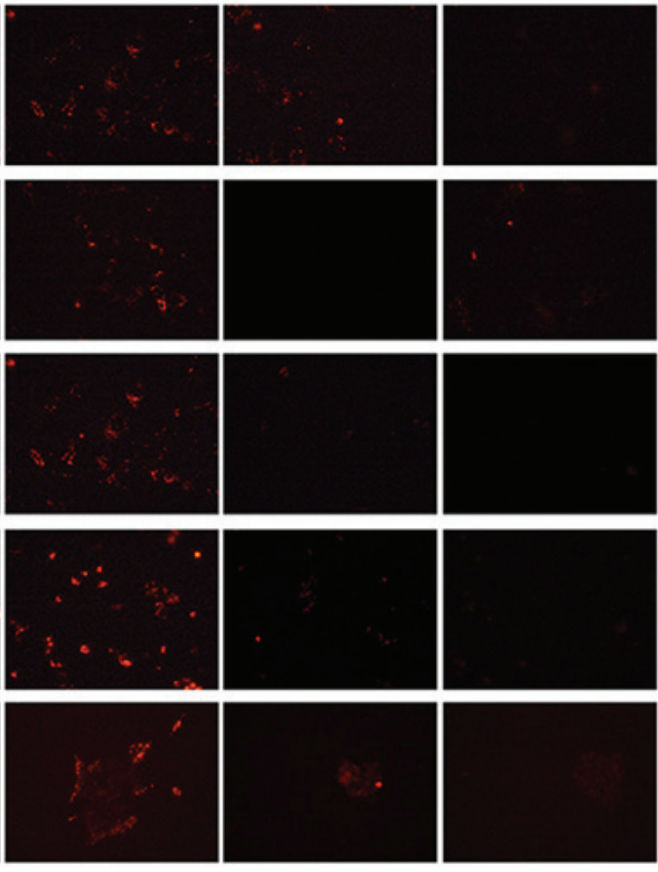

Figure 3. Mitotane affects mitochondrial activity in thyroid cancer cell lines. (A) Thyroid cancer cells were treated with increasing concentrations of mitotane $(0-50 \mu \mathrm{M})$ and stained with JC-1. Treatment with mitotane was associated with a dose-dependent decrease of fluorescence, indicating progressive loss of mitochondrial activity. Treatment with $30 \mu \mathrm{M}$ mitotane resulted in inhibition of mitochondrial membrane potential in all examined thyroid cancer cell lines. (B) Detection of mitochondrial proteins NDUFA1 (complex 1), SDHA (complex 2), cytochrome $c$, COX4 (complex 4) and ATP5B (complex 5) in thyroid cancer cell lines following 24-48-h treatment with $0-100 \mu \mathrm{M}$ mitotane by western blot analysis. Treatment led to a decrease in the levels of proteins regulating oxidative respiration in a dose-dependent and cell type-specific manner. (C) The effects of mitotane on ATP5B mRNA levels in thyroid cancer cells. The relative mRNA levels of ATP5B were evaluated following normalization to $18 \mathrm{~S}$ RNA levels. Thyroid cancer cell treatment with $50 \mu \mathrm{M}$ mitotane for $24 \mathrm{~h}$ resulted in downregulation of ATP5B expression, with the most marked effects observed in the medullary thyroid cancer-derived TT cells. Relative expression is presented normalized to the untreated control. ${ }^{*} \mathrm{P}<0.05$ and ${ }^{* *} \mathrm{P}<0.01$ versus untreated control. The data are presented as the mean \pm standard deviation. NDUFA1, NADH dehydrogenase $1 \alpha-1$; SDHA, succinate dehydrogenase flavoprotein subunit; COX4, cytochrome $c$ oxidase subunit 4; ATP5B, ATP synthase subunit $\beta$. 

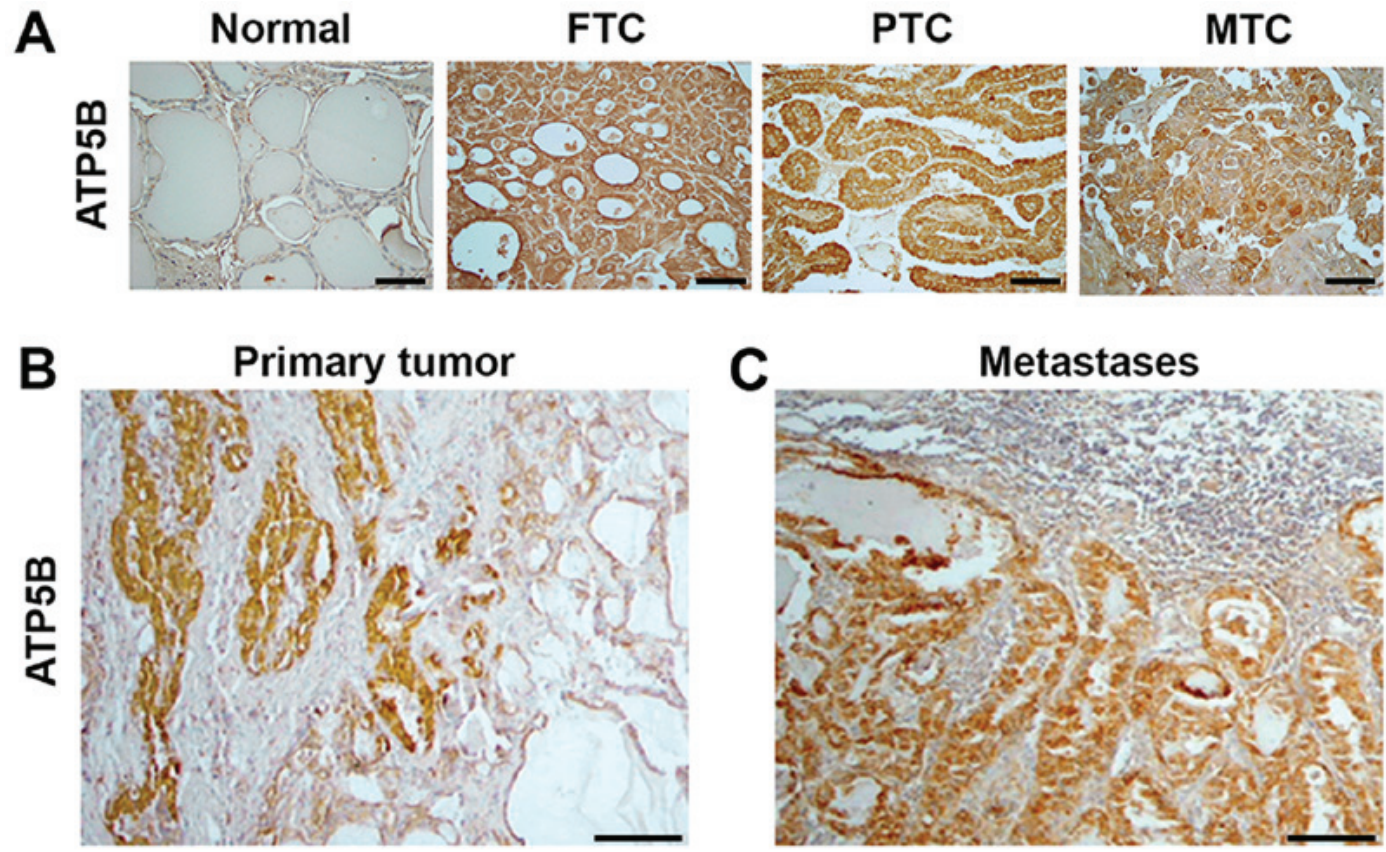

Figure 4. ATP5B expression in human thyroid tissue samples. Immunostaining with anti-ATP5B indicating (A) minimal expression of ATP5B in normal tissue samples, compared with the strong, homogeneous cytoplasmic expression in FTC, PTC and MTC samples (magnification, x400; scale bars, $100 \mu \mathrm{m}$ ), (B) expression of ATP5B in primary PTC, and (C) expression of ATP5B in corresponding lymph node metastasis tissue (magnification, x100; scale bars, $100 \mu \mathrm{m}$ ). ATP5B, ATP synthase subunit $\beta$; FTC, follicular thyroid cancer; PTC, papillary thyroid cancer; MTC, medullary thyroid cancer.

$50 \mu \mathrm{M}$ mitotane for $24 \mathrm{~h}$ was associated with downregulated ATP5B transcription in all TC cells. The relative mRNA levels of ATP5B in the FTC-133, BCPAP, SW1736, C643 and TT cells decreased by 0.71-, 0.62-, 0.7-, 0.8- and 0.58-fold, respectively, compared with the corresponding untreated controls (Fig. 3C). These data demonstrate that mitotane targets mitochondria in TC cells, and mitochondrial membrane depolarization is a common event following exposure to this compound.

Expression of ATP5B in human TC specimens. Since the cytotoxic effects of mitotane included a decrease of ATP5B expression in TC cell lines, the expression of this protein was further investigated in human thyroid tissue samples. Immunostaining with anti-ATP5B was performed in 100 commercially available thyroid tissue samples: 10 normal thyroid, 20 FTC, 44 PTC, 6 PDTC and 20 MTC samples. ATP5B expression was detected in the cytoplasm of normal thyroid cells. Compared with the detection in the normal thyroid tissue, ATP5B expression was increased in 6/20 (30\%) FTC, 29/44 (65\%) PTC, 2/6 (33\%) PDTC and 16/20 (80\%) MTC samples. Representative immunostaining images are displayed in Fig. 4. The pattern of immunostaining with anti-ATP5B in PDTCs was similar to that in FTCs (data not shown). The intensity of staining with anti-ATP5B was significantly higher in TCs as compared to normal thyroid $(\mathrm{P}=0.001)$. No significant association was observed between the level of ATP5B immunostaining and the sex of the patients, tumor size or presence of metastases at the time of surgery. The intensity of anti-ATP5B staining among the FTC, PTC and PDTC samples was not significantly different, but was higher in MTC samples compared with those from FTC tissue $(\mathrm{P}=0.01)$.

Furthermore, ATP5B mRNA levels were determined in 16 thyroid tumor samples (12 PTC, 3 FTC and 1 MTC) and in corresponding normal thyroid tissue from each patient. No significant difference was observed between the ATP5B expression in the tumor samples and that in the corresponding normal thyroid tissue. Analysis of ATP5B mRNA in cases of lymph node metastases (5 cases) demonstrated that, in the metastatic tissue, the mRNA levels of ATP5B were similar to those detected in the corresponding primary tumors.

Notably, the results of immunostaining with anti-ATP5B in tumors and in adjacent normal thyroid were not in agreement with the RT-qPCR data. The ATP5B protein levels were higher in 5/12 PTC, 1/3 FTC and in the MTC sample when compared with the corresponding normal thyroid tissue. As demonstrated in Fig. 4B, prominent ATP5B immunostaining was detected in cancer cells, but not in adjacent to the tumor normal thyroid. Positive staining with anti-ATP5B was also found in metastatic lesions and intensity of staining was similar those observed in corresponding primary tumors (Fig. 4C).

UCSC Xena was used to explore functional genomic data sets for links between ATP5B expression and clinical prognosis. This analysis revealed no significant associations between the ATP5B mRNA levels in TC and survival probability (data not shown).

\section{Discussion}

Repositioning of already established, effective medications for the treatment of cancer represents a feasible way to accelerate the translation of experimental findings into clinical practice. In the current study, mitotane was examined as a new therapeutic agent against TC. To the best of our knowledge, this is the first study reporting the effects of mitotane on TC cells. The present results demonstrated that mitotane is toxic for these cells. It was revealed that mitotane-induced toxicity implicates 
multiple mechanisms, including induction of ER stress, inhibition of the mitochondrial membrane potential, DNA damage and apoptosis. The study also provided evidence that a molecular target for mitotane, mitochondrial ATP5B, is upregulated in human types of TC.

Repositioning of medications requires that the drug is effective for its new purpose within its already established therapeutic range, which for mitotane is $14-20 \mu \mathrm{g} / \mathrm{ml}(19,24)$. Several studies have reported that the effectiveness of mitotane treatment is linked to the serum concentration of the medication, with concentrations $\geq 14 \mu \mathrm{g} / \mathrm{ml}$ being favorably associated with patient survival and response to treatment (25-27). Pharmacokinetic studies have demonstrated that the therapeutic range of $14-20 \mu \mathrm{g} / \mathrm{ml}$ (corresponding to $40-60 \mu \mathrm{M})$ is achieved in only $50 \%$ of patients with ACC, and for that reason several specialists now use a therapeutic window of $10-30 \mu \mathrm{g} / \mathrm{ml}$, as this represents the only predictive marker of antitumor response to date (28).

In the present study, the proliferation and cell viability experiments demonstrated that mitotane is toxic to TC cells. These findings are consistent with previous reports demonstrating that mitotane could be toxic for ACC cells $(22,29)$, as well as for breast, lung and colon cancer cell lines (30). In the TC cell lines used herein, low doses of mitotane triggered ER stress, and increasing concentrations led to the induction of DNA damage and apoptosis. These findings are in accordance with previously reported data demonstrating that accumulation of unfolded proteins within the ER results in the release of calcium, which in turn triggers the initiation of apoptosis (31). A previous study revealed that mitotane induced ER stress through sterol-O-acyltransferase 1/mitochondrial acetyl-CoA acetyltransferase inhibition, which in turn led to apoptosis (32). Notably, microscopic evidence of toxicity following mitotane exposure has been reported in neoplastic adrenal cells (cytoplasmic vacuoles, cell shrinking and partial cell detachment), similar to the results presented in the current study (33).

Growing evidence suggests that the effects of mitotane are closely associated with mitochondria. It has been reported that mitotane induces a mitochondrial respiratory chain defect by inhibiting COX2 and COX4I1 (21). Treatment with mitotane also altered expression of mitochondria-associated membrane proteins, including ATPase family AAA domain-containing protein $3 \mathrm{~A}$ and translocator protein/peripheral-type benzodiazepine receptor (34). It has been suggested that reactive oxygen species (ROS) can act as messengers among mitochondria, leading to mitochondrial membrane depolarization and further ROS release, eventually causing global depolarization if the stressor is not removed (35).

The present study revealed that the initial event following treatment with mitotane was inhibition of the mitochondrial membrane potential. Mitochondrial membrane depolarization was observed at a concentration of $30 \mu \mathrm{M}$, which is well below the current therapeutic range for $\mathrm{ACC}(50 \mu \mathrm{M})$, suggesting that mitotane may be effective for TC at therapeutically achievable concentrations. The western blotting and immunohistochemistry data demonstrated that the mitochondrial respiratory chain enzymes are targets of mitotane. Mitochondrial localization following mitotane exposure was altered in TC cells, as demonstrated by JC-1 staining, corroborating findings from
ACC cells. Mitotane-treated ACC cells exhibit a more punctiform pattern in the mitochondrial compartment, possibly resulting from disequilibrium between mitochondrial fission and fusion $(21,36)$.

One intriguing finding of the current study is the differential response of various TC cell lines to mitotane treatment. BCPAP, SW1736 and TT cells were the most sensitive to the drug. These TC cell lines are characterized by constitutive activation of the MAPK/ERK signaling pathway as result of BRAF (BCPAP and SW1736 cells) or RET (TT cells) mutations. One of the main questions that should be addressed by future studies is whether the mutational status in TC serves a significant role in the response to mitotane. It will also be important to determine whether mitochondria-enriched TC cells, such as those in Hürthle cell thyroid carcinomas, would be sensitive to treatment with this compound.

Since the present in vitro data suggested that mitochondrial proteins could be molecular targets for mitotane, ATP5B expression in human TC tissue samples was examined. This revealed that ATP5B expression was increased in cancer versus normal thyroid tissue, particularly in MTC tissue samples. This finding may provide an alternate explanation as to why TC cells derived from MTC (TT cells) were the most sensitive to the effects of mitotane in the present in vitro experiments. These results suggest that this drug could be effective in targeting aggressive types of TC.

Despite the documented effectiveness in the management of ACC, the tolerability of the medication is limited by its side-effect profile. The most common side effects are gastrointestinal, including nausea, vomiting, diarrhea and anorexia, occurring in as many as $78 \%$ of treated patients (37). Other side effects include endocrinological (secondary adrenal insufficiency and thyroid dysfunction), neurological (confusion, ataxia and tremors) and metabolic (hypercholesterolemia, hyperbilirubinemia and rash) issues $(38,39)$. Certainly, the adrenolytic effects of mitotane and the enhanced production of cortisol-binding globulin would lead to hypocortisolism, which would be the most clinically significant side effect.

The majority of studies on mitotane have been performed on cell lines that are derived from ACC, such as NCI-H295, H295R or Fang- 8 cells, or cells that are derived from metastasis to the adrenals, for example SW-13 cells. However, canine primary adrenal cell cultures have been used to demonstrate loss of steroidogenesis and cell death in response to mitotane, among other toxins (40). Limited studies have also been performed on thyroid function, revealing that mitotane can cause central hypothyroidism by inhibiting thyrotrophic cell viability, and thyroid-stimulating hormone expression and secretion $(41,42)$.

Despite the fact that mitotane has a significant side-effect profile as discussed above, it is important to mention that, from the clinical standpoint, it is manageable. Adrenal insufficiency is probably the most significant side effect, and it is well established that it can be treated with supraphysiological replacement with hydrocortisone, as cytochrome P450 3A4 induction by mitotane results in rapid inactivation of $>50 \%$ of administered hydrocortisone (43).

TC cells lines that were used in the current study may represent useful models for undifferentiated types of cancer (44). 
Previous studies have demonstrated that these cell lines derived from differentiated and undifferentiated tumor types have evolved similar phenotypes in vitro, with gene expression profiles that are closest to in vivo undifferentiated tumors $(44,45)$.

There are limited treatment options for the management of patients with ATC $(8,9)$. Many studies have used a variety of chemotherapeutic agents for the treatment of patients with this condition (46). The majority, however, concluded that chemotherapy did not improve survival $(46,47)$. Patients with ATC have extremely short survival times, and for many of them, only palliative care can be offered to manage symptoms of pain, bleeding, nausea, dyspnea and depression.

Although the present results should be considered in the context of a benefit/harm discussion of treatment options between the physician and patient, it is our opinion that patients with aggressive medullary, poorly differentiated and anaplastic types of TC may benefit from the administration of mitotane, while exhibiting a significant, but manageable, side effect profile.

The current study is the first to demonstrate the in vitro activity of mitotane against aggressive TC. However, one limiting factor is the lack of an animal model that would provide valuable information more closely resembling the human macroenvironment. In that regard, in vivo experiments in a xenograft TC animal model that will better elucidate the cytotoxic effects of mitotane are being designed. Furthermore, a more direct evaluation of the functional mitochondrial activity in TC cells will be performed, since the current study has established that mitotane affects the expression of several mitochondrial proteins. The results of whether treatment with mitotane is more effective in cells relying more heavily on oxidative phosphorylation will be presented in a separate manuscript.

In summary, the present findings provide evidence that mitotane inhibits proliferation, promotes apoptosis and induces DNA damage in TC cells. This drug also induces ER stress and inhibits expression of mitochondrial membrane enzymes, most notably ATP5B. On the basis of these findings, we propose that mitotane, an FDA-approved medication for ACC, may be used against aggressive TC and warrants further clinical studies.

\section{Acknowledgements}

The views expressed in this article are those of the authors and do not reflect the official policy or position of the US Air Force, the Department of Defense or the US government. Title 17 U.S.C. 105 provides that 'copyright protection under this title is not available for any work of the United States Government'. Title 17 U.S.C. 101 defines a United States government work as 'a work prepared by a military service member or employee of the United States government as part of that person's official duties'. This work was prepared as part of the official duties of $\mathrm{KJ}, \mathrm{VV}, \mathrm{JC}$ and AP.

\section{Funding}

This study was supported by the International Endocrine Research Fellowship Program, MedStar Health Research Institute and MedStar Washington Hospital Center.

\section{Availability of data and materials}

The datasets used and/or analyzed during the current study are available from the corresponding author on reasonable request.

\section{Authors' contributions}

$\mathrm{AB}$ and $\mathrm{KJ}$ acquired the data and drafted the manuscript. $\mathrm{AB}$, AP, JC, VH, and VV collected tissue samples and performed the in vitro experiments. $\mathrm{KJ}, \mathrm{GK}$, and $\mathrm{KB}$ analyzed and interpreted the data, and performed statistical analysis. $\mathrm{VV}, \mathrm{KJ}$, $\mathrm{KB}$ and LW reviewed the manuscript, figures and tables. All authors read and approved the final manuscript.

\section{Ethics approval and consent to participate}

This study was approved by the Institutional Review Board and the Human Use Committee of the Uniformed Services University of the Health Sciences (approval no. FG86GI-S14).

\section{Patient consent for publication}

Not applicable.

\section{Competing interests}

The authors declare that they have no competing interests.

\section{References}

1. Ferlay J, Soerjomataram I, Dikshit R, Eser S, Mathers C, Rebelo M, Parkin DM, Forman D and Bray F: Cancer incidence and mortality worldwide: Sources, methods and major patterns in GLOBOCAN 2012. Int J Cancer 136: E359-E386, 2015.

2. Ahn HS, Kim HJ and Welch HG: Korea's thyroid-cancer 'epidemic' - screening and overdiagnosis. N Engl J Med 371: 1765-1767, 2014.

3. Chen AY, Jemal A and Ward EM: Increasing incidence of differentiated thyroid cancer in the United States, 1988-2005. Cancer 115: 3801-3807, 2009

4. Schlumberger MJ: Papillary and follicular thyroid carcinoma. N Engl J Med 338: 297-306, 1998.

5. Sherman SI: Thyroid carcinoma. Lancet 361: 501-511, 2003.

6. Muresan MM, Olivier P, Leclère J, Sirveaux F, Brunaud L, Klein M, Zarnegar R and Weryha G: Bone metastases from differentiated thyroid carcinoma. Endocr Relat Cancer 15: 37-49, 2008.

7. Tubiana M, Schlumberger M, Rougier P, Laplanche A, Benhamou E, Gardet P, Caillou B, Travagli JP and Parmentier C: Long-term results and prognostic factors in patients with differentiated thyroid carcinoma. Cancer 55: 794-804, 1985.

8. Smallridge RC and Copland JA: Anaplastic thyroid carcinoma: Pathogenesis and emerging therapies. Clin Oncol (R Coll Radiol) 22: 486-497, 2010.

9. Smallridge RC,Ain KB, Asa SL, Bible KC,Brierley JD, Burman KD, Kebebew E, Lee NY, Nikiforov YE, Rosenthal MS, et al; American Thyroid Association Anaplastic Thyroid Cancer Guidelines Taskforce: American Thyroid Association guidelines for management of patients with anaplastic thyroid cancer. Thyroid 22: 1104-1139, 2012.

10. Nosé V: Familial thyroid cancer: A review. Mod Pathol 24 (Suppl 2): S19-S33, 2011.

11. Williams SD, Birch R and Einhorn LH: Phase II evaluation of doxorubicin plus cisplatin in advanced thyroid cancer: A Southeastern Cancer Study Group Trial. Cancer Treat Rep 70: 405-407, 1986

12. Bikas A, Vachhani S, Jensen K, Vasko V and Burman KD: Targeted therapies in thyroid cancer: An extensive review of the literature. Expert Rev Clin Pharmacol 9: 1299-1313, 2016.

13. Kushchayeva Y, Jensen K, Burman KD and Vasko V: Repositioning therapy for thyroid cancer: New insights on established medications. Endocr Relat Cancer 21: R183-R194, 2014. 
14. Jensen K, Bikas A, Patel A, Kushchayeva Y, Costello J, McDaniel D, Burman K and Vasko V: Nelfinavir inhibits proliferation and induces DNA damage in thyroid cancer cells. Endocr Relat Cancer 24: 147-156, 2017.

15. Kushchayeva Y, Jensen K, Recupero A, Costello J, Patel A, Klubo-Gwiezdzinska J, Boyle L, Burman K and Vasko V: The HIV protease inhibitor nelfinavir down-regulates RET signaling and induces apoptosis in medullary thyroid cancer cells. J Clin Endocrinol Metab 99: E734-E745, 2014.

16. Klubo-Gwiezdzinska J, Jensen K, Costello J, Patel A, Hoperia V, Bauer A, Burman KD, Wartofsky L and Vasko V: Metformin inhibits growth and decreases resistance to anoikis in medullary thyroid cancer cells. Endocr Relat Cancer 19: 447-456, 2012.

17. Thakur S, Daley B, Gaskins K, Vasko VV, Boufraqech M, Patel D, Sourbier C, Reece J, Cheng SY, Kebebew E, et al: Metformin targets mitochondrial glycerophosphate dehydrogenase to control rate of oxidative phosphorylation and growth of thyroid cancer in vitro and in vivo. Clin Cancer Res 24: 4030-4043, 2018

18. Baudry C, Coste J, Bou Khalil R, Silvera S, Guignat L, Guibourdenche J, Abbas H, Legmann P, Bertagna X and Bertherat J: Efficiency and tolerance of mitotane in Cushing's disease in 76 patients from a single center. Eur J Endocrinol 167: 473-481, 2012.

19. Berruti A, Baudin E, Gelderblom H, Haak HR, Porpiglia F, Fassnacht $\mathrm{M}$ and Pentheroudakis G; ESMO Guidelines Working Group: Adrenal cancer: ESMO Clinical Practice Guidelines for diagnosis, treatment and follow-up. Ann Oncol 23 (Suppl 7): vii131-vii138, 2012.

20. Henley DJ, van Heerden JA, Grant CS, Carney JA and Carpenter PC: Adrenal cortical carcinoma - a continuing challenge. Surgery 94: 926-931, 1983.

21. Hescot S, Slama A, Lombès A, Paci A, Remy H, Leboulleux S, Chadarevian R, Trabado S, Amazit L, Young J, et al: Mitotane alters mitochondrial respiratory chain activity by inducing cytochrome $c$ oxidase defect in human adrenocortical cells. Endocr Relat Cancer 20: 371-381, 2013.

22. Poli G, Guasti D, Rapizzi E, Fucci R, Canu L, Bandini A, Cini N, Bani D, Mannelli M and Luconi M: Morphofunctional effects of mitotane on mitochondria in human adrenocortical cancer cells. Endocr Relat Cancer 20: 537-550, 2013.

23. Livak KJ and Schmittgen TD: Analysis of relative gene expression data using real-time quantitative PCR and the 2(-Delta Delta C(T)) Method. Methods 25: 402-408, 2001.

24. Schteingart DE, Doherty GM, Gauger PG, Giordano TJ, Hammer GD, Korobkin M and Worden FP: Management of patients with adrenal cancer: Recommendations of an international consensus conference. Endocr Relat Cancer 12: 667-680, 2005.

25. Haak HR, Hermans J, van de Velde CJ, Lentjes EG, Goslings BM Fleuren GJ and Krans HM: Optimal treatment of adrenocortical carcinoma with mitotane: Results in a consecutive series of 96 patients. Br J Cancer 69: 947-951, 1994.

26. Hermsen IG, Fassnacht M, Terzolo M, Houterman S, den Hartigh J, Leboulleux S, Daffara F, Berruti A, Chadarevian R, Schlumberger M, et al: Plasma concentrations of o,p'DDD, $\mathrm{o}, \mathrm{p}^{\prime} \mathrm{DDA}$, and $\mathrm{o}, \mathrm{p}^{\prime} \mathrm{DDE}$ as predictors of tumor response to mitotane in adrenocortical carcinoma: Results of a retrospective ENS@T multicenter study. J Clin Endocrinol Metab 96: 1844-1851, 2011

27. van Slooten H, Moolenaar AJ, van Seters AP and Smeenk D: The treatment of adrenocortical carcinoma with o,p'-DDD: Prognostic implications of serum level monitoring. Eur J Cancer Clin Oncol 20: 47-53, 1984.

28. Baudin E; Endocrine Tumor Board of Gustave Roussy: Adrenocortical carcinoma. Endocrinol Metab Clin North Am 44: 411-434, 2015

29. Lehmann TP, Wrzesiński T and Jagodziński PP: The effect of mitotane on viability, steroidogenesis and gene expression in NCI-H295R adrenocortical cells. Mol Med Rep 7: 893-900, 2013.

30. Waszut U, Szyszka P and Dworakowska D: Understanding mitotane mode of action. J Physiol Pharmacol 68: 13-26, 2017.

31. Pinton P, Giorgi C, Siviero R, Zecchini E and Rizzuto R: Calcium and apoptosis: ER-mitochondria $\mathrm{Ca} 2+$ transfer in the control of apoptosis. Oncogene 27: 6407-6418, 2008.
32. Sbiera S, Leich E, Liebisch G, Sbiera I, Schirbel A, Wiemer L, Matysik S, Eckhardt C, Gardill F, Gehl A, et al: Mitotane inhibits sterol-O-acyl transferase 1 triggering lipid-mediated endoplasmic reticulum stress and apoptosis in adrenocortical carcinoma cells. Endocrinology 156: 3895-3908, 2015.

33. Fang VS: Cytotoxic activity of 1-(o-chlorophenyl)-1-(p-chlo rophenyl)-2,2-dichloroethane (mitotane) and its analogs on feminizing adrenal neoplastic cells in culture. Cancer Res 39: 139-145, 1979.

34. Hescot S, Amazit L, Lhomme M, Travers S, DuBow A, Battini S, Boulate G, Namer IJ, Lombes A, Kontush A, et al: Identifying mitotane-induced mitochondria-associated membranes dysfunctions: Metabolomic and lipidomic approaches. Oncotarget 8: 109924-109940, 2017.

35. Whelan SP and Zuckerbraun BS: Mitochondrial signaling: Forwards, backwards, and in between. Oxid Med Cell Longev 2013: 351613, 2013.

36. Chen $\mathrm{H}$ and Chan DC: Physiological functions of mitochondrial fusion. Ann N Y Acad Sci 1201: 21-25, 2010.

37. Hutter AM Jr and Kayhoe DE: Adrenal cortical carcinoma. Clinical features of 138 patients. Am J Med 41: 572-580, 1966

38. Veytsman I, Nieman L and Fojo T: Management of endocrine manifestations and the use of mitotane as a chemotherapeutic agent for adrenocortical carcinoma. J Clin Oncol 27: 4619-4629, 2009.

39. Creemers SG, Hofland LJ, Korpershoek E, Franssen GJ, van Kemenade FJ, de Herder WW and Feelders RA: Future directions in the diagnosis and medical treatment of adrenocortical carcinoma. Endocr Relat Cancer 23: R43-R69, 2016.

40. Morishita K, Okumura H, Ito N and Takahashi N: Primary culture system of adrenocortical cells from dogs to evaluate direct effects of chemicals on steroidogenesis. Toxicology 165: 171-178, 2001.

41. Zatelli MC, Gentilin E, Daffara F, Tagliati F, Reimondo G, Carandina G, Ambrosio MR, Terzolo M and Degli Uberti EC: Therapeutic concentrations of mitotane (o,p'-DDD) inhibit thyrotroph cell viability and TSH expression and secretion in a mouse cell line model. Endocrinology 151: 2453-2461, 2010.

42. Russo M, Scollo C, Pellegriti G, Cotta OR, Squatrito S, Frasca F, Cannavò $S$ and Gullo D: Mitotane treatment in patients with adrenocortical cancer causes central hypothyroidism. Clin Endocrinol (Oxf) 84: 614-619, 2016.

43. Chortis V, Taylor AE, Schneider P, Tomlinson JW, Hughes BA, O'Neil DM, Libé R, Allolio B, Bertagna X, Bertherat J, et al: Mitotane therapy in adrenocortical cancer induces CYP3A4 and inhibits $5 \alpha$-reductase, explaining the need for personalized glucocorticoid and androgen replacement. J Clin Endocrinol Metab 98: 161-171, 2013.

44. van Staveren WC, Solís DW, Delys L, Duprez L, Andry G, Franc B, Thomas G, Libert F, Dumont JE, Detours V, et al: Human thyroid tumor cell lines derived from different tumor types present a common dedifferentiated phenotype. Cancer Res 67: 8113-8120, 2007.

45. Saiselet M, Floor S, Tarabichi M, Dom G, Hébrant A, van Staveren WC and Maenhaut C: Thyroid cancer cell lines: An overview. Front Endocrinol (Lausanne) 3: 133, 2012.

46. Salehian B, Liem SY, Mojazi Amiri H and Maghami E: Clinical Trials in Management of Anaplastic Thyroid Carcinoma; Progressions and Set Backs: A Systematic Review. Int J Endocrinol Metab 17: e67759, 2019.

47. Sosa JA, Elisei R, Jarzab B, Balkissoon J, Lu SP, Bal C, Marur S, Gramza A, Yosef RB, Gitlitz B, et al: Randomized safety and efficacy study of fosbretabulin with paclitaxel/carboplatin against anaplastic thyroid carcinoma. Thyroid 24: 232-240, 2014.

This work is licensed under a Creative Commons Attribution-NonCommercial-NoDerivatives 4.0 International (CC BY-NC-ND 4.0) License. 